\title{
Air quality modelling using the Met Office Unified Model (AQUM OS24-26): model description and initial evaluation
}

\author{
N. H. Savage, P. Agnew, L. S. Davis, C. Ordóñez, R. Thorpe, C. E. Johnson, F. M. O’Connor, and M. Dalvi \\ Met Office, Fitzroy Road, Exeter, EX1 3PB, UK \\ Correspondence to: N. H. Savage (nicholas.savage@metoffice.gov.uk)
}

Received: 24 August 2012 - Published in Geosci. Model Dev. Discuss.: 10 October 2012

Revised: 6 February 2013 - Accepted: 19 February 2013 - Published: 12 March 2013

\begin{abstract}
The on-line air quality model AQUM (Air Quality in the Unified Model) is a limited-area forecast configuration of the Met Office Unified Model which uses the UKCA (UK Chemistry and Aerosols) sub-model. AQUM has been developed with two aims: as an operational system to deliver regional air quality forecasts and as a modelling system to conduct air quality studies to inform policy decisions on emissions controls. This paper presents a description of the model and the methods used to evaluate the performance of the forecast system against the automated UK surface network of air quality monitors. Results are presented of evaluation studies conducted for a year-long period of operational forecast trials and several past cases of poor air quality episodes. The results demonstrate that AQUM tends to over-predict ozone $\left(\sim 8 \mu \mathrm{g} \mathrm{m}^{-3}\right.$ mean bias for the year-long forecast), but has a good level of responsiveness to elevated ozone episode conditions - a characteristic which is essential for forecasting poor air quality episodes. AQUM is shown to have a negative bias for $\mathrm{PM}_{10}$, while for $\mathrm{PM}_{2.5}$ the negative bias is much smaller in magnitude. An analysis of speciated $\mathrm{PM}_{2.5}$ data during an episode of elevated particulate matter (PM) suggests that the PM bias occurs mainly in the coarse component. The sensitivity of model predictions to lateral boundary conditions (LBCs) has been assessed by using LBCs from two different global reanalyses and by comparing the standard, single-nested configuration with a configuration having an intermediate European nest. We conclude that, even with a much larger regional domain, the LBCs remain an important source of model error for relatively long-lived pollutants such as ozone. To place the model performance in context we compare AQUM ozone forecasts with those of another forecasting system, the MACC (Monitoring Atmospheric
\end{abstract}

Composition and Climate) ensemble, for a 5-month period. An analysis of the variation of model skill with forecast lead time is presented and the insights this provides to the relative sources of error in air quality modelling are discussed.

\section{Introduction}

Regional air quality models have evolved rapidly in sophistication over the last ten years. Off-line chemical transport models (CTMs), configured with constant or climatological chemical lateral boundary conditions (LBCs) have been superseded by regional models coupled to global models, with the latter providing spatially and temporally evolving boundary fluxes of key chemical species. The GEMS project (Global and regional Earth-system atmosphere Monitoring using Satellite and in-situ data - see Hollingsworth et al., 2008) and its successor MACC (Monitoring Atmospheric Composition and Climate) have played a major role in these developments with the creation of a system of global models for reactive gases and aerosols (operated by the European Centre for Medium-Range Weather Forecasting - ECMWF) providing boundary fluxes to European regional air quality models. The ECMWF global models and some of the more advanced regional models incorporate data assimilation of key chemical and aerosol species, thus adding a further degree of sophistication. Another example of increasing model sophistication concerns the transition from off-line to online modelling. In the latter the meteorological and chemical evolution of the atmosphere are modelled within the same system, with the potential to include feedbacks of composition on meteorology. Examples of possible feedbacks include 
direct aerosol effects due to radiation scattering and indirect effects such as the nucleation of cloud droplets by particulates. A new collaborative project - COST-ES1004 - has been initiated with the objective of clarifying and quantifying the improvements to meteorological forecasts by including on-line composition modelling.

The UK Met Office Unified Model (MetUM) is a weather and climate modelling system which is used across a very wide range of spatial and temporal scales, from short-range weather forecasting at $1.5 \mathrm{~km}$ resolution (Price et al., 2011) to multi-decadal simulations in an Earth system model configuration (Collins et al., 2011). We have developed a configuration of the MetUM for use as an on-line regional air quality model - AQUM (Air Quality in the Unified Model). This model builds on the work of the United Kingdom Chemistry and Aerosols (UKCA) project (Morgenstern et al., 2009; O'Connor et al., 2013), which has constructed a new framework for atmospheric composition modelling within the MetUM. The type of parameterisations used in UKCA and the level of complexity in representing the Earth system can be selected as appropriate to the problem under investigation. AQUM has been developed to fulfil two purposes: (i) the operational delivery of daily air quality forecasts and (ii) to enable atmospheric modelling studies to address scientific and air quality policy-related questions. We have chosen to develop a chemistry and aerosol model online in the MetUM so that the feedbacks of atmospheric composition on meteorology can, in due course, be included in the weather forecast model. However, this application is not examined in this paper, which focuses exclusively on air quality modelling.

In Sect. 2 of this paper we present an overview of the AQUM modelling system. We then describe the verification methodology we have used to evaluate the model in Sect. 3. In Sect. 4 we present a summary of the evaluation studies we have carried out on both operational forecasts and particular past air quality episodes, comparing model predictions with a surface observation network. A summary of the results is presented in Sect. 5 and a short description of the model developments planned for AQUM is given.

\section{Model description}

\subsection{Physical model overview}

AQUM is currently operated with a $12-\mathrm{km}$ horizontal resolution grid covering much of Western Europe (see Fig. 9). The native model grid is on a rotated-pole coordinate system with the North Pole at latitude $37.5^{\circ}$ and longitude at $177.5^{\circ}$. There are 38 vertical levels up to a model top height of $39 \mathrm{~km}$. This would be considered high for an off-line air quality model, but for on-line modelling a height of this order is necessary for accurate modelling of the meteorological system. The resolution and domain were selected to enable regional-scale ozone and particulate matter (PM) events impacting the United Kingdom to be modelled. The model physics configuration is based on the Met Office's North Atlantic and European Model (NAE). A description of this configuration is given in Bush et al. (2006), although some further minor developments were made to the model prior to it forming the basis of the AQUM model described here.

The MetUM dynamical core is non-hydrostatic and fully compressible, and no shallow atmosphere approximations are made. Semi-implicit, semi-Lagrangian time integration methods are used and a positive definite semi-Lagrangian tracer advection scheme is used to advect aerosols and gases (Davies et al., 2005). Boundary layer mixing (including that of aerosols and gases) is parameterised with a non-local, first order closure, multi-regime scheme (Lock et al., 2000). Convection is represented with a mass flux scheme with downdraughts, momentum transport and CAPE (convective available potential energy) closure (Gregory and Rowntree, 1990). The land surface scheme, MOSES II, is a nine tile, flux-blended surface exchange approach and includes an urban tile (Essery et al., 2003). The model uses the EdwardsSlingo flexible multi-band two-stream code for long- and short-wave radiation with $6 \mathrm{SW}$ and $9 \mathrm{LW}$ bands (Edwards and Slingo, 1996). Wilson and Ballard (1999) microphysics is employed and extended to include prognostic ice and snow, rain and graupel. The model uses the diagnostic cloud scheme described by Smith (1990).

\subsection{Gas phase chemistry scheme}

The AQUM gas phase chemistry is a further development of the UKCA tropospheric chemistry scheme (O'Connor et al., 2013), but with a new chemical mechanism added specifically for regional air quality (RAQ) modelling. This RAQ mechanism includes 40 transported species ( 16 of them emitted), 18 non-advected species, 116 gas phase reactions and 23 photolysis reactions (see Supplement, Tables S1-S5). Removal by wet and dry deposition is considered for 19 and 16 species respectively (see Tables S1 and S6 in the Supplement). Unlike the standard tropospheric chemistry described in O'Connor et al. (2013), this scheme includes the oxidation of both $\mathrm{C} 2-\mathrm{C} 3$ alkenes (ethene and propene), isoprene and aromatic compounds such as toluene and o-xylene, as well as the formation of organic nitrate. It is adapted from the mechanism presented in Collins et al. (1997) with the additional reactions described in Collins et al. (1999) and some further modifications (in particular to the isoprene and aromatic chemistry mechanisms). For more details on the RAQ chemistry scheme refer to the Supplement. Note that sulphur chemistry is not currently included in the RAQ mechanism, but is treated in the aerosol scheme (see Sect. 2.3). The concentrations are updated using a backward Euler solver with a time step of $75 \mathrm{~s}$ in the studies described in this paper.

Both dry and wet deposition of gases and aerosols are calculated on-line using actual meteorology. Dry deposition is modelled via a multiple resistance approach (Wesley, 1989; 
Sanderson et al., 2007) with surface resistance terms calculated for each tile. The aerodynamic and quasi-laminar resistance are calculated based on the roughness length, canopy height and surface heat flux. Wet deposition is parameterised as a first order loss rate, calculated as a function of the model's three-dimensional convective and large-scale precipitation in a manner adapted from Giannakopoulos (1998) and Giannakopoulos et al. (1999). Photolysis rates are calculated with the on-line photolysis scheme Fast-J (Wild et al., 2000), which is coupled to the modelled liquid water and ice content, and sulphate aerosols on a time step basis.

\subsection{Aerosol scheme}

The current AQUM configuration uses the Coupled Largescale Aerosol Simulator for Studies in Climate (CLASSIC) aerosol module. A short description will be given here - for further details see Appendix A of Bellouin et al. (2011) and references therein.

The scheme contains six prognostic tropospheric aerosol types: ammonium sulphate, mineral dust, fossil fuel black carbon (FFBC), fossil fuel organic carbon (FFOC), biomass burning aerosols and ammonium nitrate. In addition, there is a diagnostic aerosol scheme for sea salt and a fixed climatology of biogenic secondary organic aerosols (BSOA) from the oxidation of terpenes from vegetation. It is a bulk aerosol scheme, where the aerosol species are treated as an external mixture and the mass of each aerosol type is the prognostic variable. Each aerosol type is assumed to have a fixed log-normal size distribution (apart from dust, which is represented with six size bins). For information on the median radius, geometric standard deviation, density and optical properties see Bellouin et al. (2011).

The model has two-way coupling of oxidants between the aerosol and gas phase chemistry schemes. Thus, emissions of sulphur dioxide $\left(\mathrm{SO}_{2}\right)$ and dimethyl sulphide (DMS) are oxidised into sulphate aerosol $\left(\mathrm{SO}_{4}^{2-}\right)$ by oxidants whose concentrations are calculated in the RAQ chemistry scheme, and the depleted oxidant fields are then passed back to the RAQ scheme to ensure consistency. Sulphate aerosol is represented by Aitken and accumulation modes and an additional tracer for sulphate dissolved in cloud droplets. Sulphate mass is assumed to all be in the form of ammonium sulphate $\left[\left(\mathrm{NH}_{4}\right)_{2} \mathrm{SO}_{4}\right]$. Emissions of DMS from oceans are parameterised as function of wind speed based on the approach of Wanninkhof (1992), with sea water concentrations from a $1^{\circ} \times 1^{\circ}$ climatology (Kettle et al., 1999).

Ammonia $\left(\mathrm{NH}_{3}\right)$ is a transported tracer in the model and is removed from the atmosphere by the formation of ammonium sulphate (as well as by dry and wet deposition); any excess ammonia can react with nitric acid $\left(\mathrm{HNO}_{3}\right)$ to form ammonium nitrate aerosol $\left(\mathrm{NH}_{4} \mathrm{NO}_{3}\right)$. Thermal decomposition of ammonium nitrate to nitric acid and ammonia is permitted according to the equilibrium model described by Ackermann et al. (1995). Nitric acid concentrations are derived from the
RAQ scheme and depleted by nitrate aerosol formation. The mass of nitrate aerosol formed goes into an accumulation mode and cloud formation transforms some of the accumulation mode into the dissolved mode, as with sulphate.

The mineral dust scheme has six size bins covering radii from $0.0316 \mu \mathrm{m}$ to $3.16 \mu \mathrm{m}$. The emissions fluxes depend on vegetation fraction, soil roughness length and moisture, and near-surface wind speeds. The dust in these six bins is transported and deposited by gravitational settling, turbulence and below-cloud scavenging.

FFBC, FFOC and biomass burning aerosols have three modes - fresh, aged and in-cloud. Ageing is represented as an exponential decay. Sea salt is represented in a diagnostic manner with number concentrations over the open ocean calculated as a function of the wind speed at a height of $10 \mathrm{~m}$ (O'Dowd et al., 1999). Biogenic secondary organic aerosols from the oxidation of terpenes are included as a three-dimensional monthly mean climatology at $5^{\circ} \times 5^{\circ}$ resolution (Derwent et al., 2003).

The direct radiative effects of all aerosols are included in the model by use of wavelength dependent scattering and absorption coefficients calculated off-line according to Mie theory. The off-line calculations include the effects of hygroscopic growth for the sulphate, sea salt, nitrate, biomass burning, FFOC and biogenic aerosols with each aerosol type assumed to have a fixed size distribution and optical properties. All aerosol species except mineral dust and FFBC are considered to act as cloud condensation nuclei. The parameterisations of the first and second indirect effects are as described by Jones et al. (2001). Although aerosol couplings to meteorological processes are included in our model configuration, the impact of this on meteorology is not addressed in this paper, but will be examined in a subsequent publication.

\subsection{Lateral boundary conditions}

Lateral boundary conditions use the method of Davies (1976), which involves relaxing the interior flow near the boundaries towards the externally prescribed flow. Relaxation involves blending of the LBCs and the limited-area model (LAM) over several grid points. For further details see Davies (2013).

Model LBCs are a combination of chemistry and aerosol data from the GEMS or MACC global models (Flemming et al., 2009) and meteorological data from Met Office weather forecast models. The use of meteorological data from the Met Office models improves consistency with the dynamics of the AQUM model. Meteorological LBCs (and initial conditions) come from the MetUM global model forecasts (for case studies) or from the NAE (for operational forecasts). For pragmatic reasons the reanalyses and forecasts produced by the GEMS and MACC projects have been used to provide boundary conditions for the composition fields. This avoids the computational and maintenance costs of running an operational global model chemistry and aerosol 
configuration, and benefits from the data assimilation carried out by the GEMS and MACC projects. A reanalysis prepared as part of the GEMS project was used to provide chemical LBCs for the case studies we have conducted, whilst real time MACC global model fields are used for the AQUM operational forecasts. The sensitivity of AQUM forecasts to chemical LBCs is discussed further in Sect. 4.3.

\subsection{Model initialisation and run cycle}

For the period of the model evaluations described in Sect. 4, the operational forecast model ran once per day out to $48 \mathrm{~h}$ ahead (although the system has since been upgraded and now provides forecasts out to 5 days ahead). The initial conditions for chemistry and aerosol species for a new AQUM forecast run are taken from the $T+24$ forecast of the previous model run. No independent data assimilation cycle was used in the forecasts. However, the initial conditions for the meteorology used Met Office analyses from the NAE model and so inherit assimilated fields for meteorological parameters produced using 4-D-variational assimilation. There is no data assimilation of chemical species either directly or indirectly, although the chemical LBCs from the GEMS/MACC global model benefit from the data assimilation within those models.

\subsection{Emissions}

The anthropogenic pollutant emissions used in AQUM are derived from three datasets. The highest resolution emissions data are from the UK National Atmospheric Emissions Inventory (NAEI, MacCarthy et al., 2011), which has a 1-km resolution and covers the UK only. Outside of the UK, emissions are taken from the European Monitoring and Evaluation Programme (EMEP) emissions datasets, which cover Europe at 50-km resolution (Mareckova et al., 2010, and similar reports for previous years). These EMEP emission fields are not further down-scaled with surrogates (such as population density), but are taken as they are. Finally, a 5-km resolution gridded shipping emissions dataset produced by Entec UK Ltd on behalf of Defra (Whall et al., 2010) is used to represent emissions for waters around the UK. Where they overlap, shipping data from Entec replaces data from the NAEI and EMEP SNAP sector 8 ("other mobile sources and machinery") in the NOS ("North Sea") and ATL ("remaining North-East Atlantic region") regions. This process ensures there is no duplication of shipping emissions. The Entec dataset was only compiled for 2007 , so for other years these data are scaled according to published totals from EMEP. Data from all three sources are interpolated to the AQUM $12 \mathrm{~km}$ grid prior to merging. The main benefits of the process we have adopted of merging data from 3 different sources are (i) the NAEI and EMEP data are updated on an annual basis; (ii) we ensure that the highest resolution datasets available for the UK are used. The use of a lower resolution dataset over Europe is not a serious limitation: numerical diffusion on the 12-km AQUM grid inherently disperses the emissions at source, and by the time any emissions from Europe reach the UK they have generally diffused in the atmosphere to an extent such that any detailed "memory" of the source spatial distribution has been lost.

Six key families of pollutants are provided in the emissions datasets described above: carbon monoxide (CO), sulphur oxide gases $\left(\mathrm{SO}_{\mathrm{x}}\right)$, volatile organic compounds (VOCs), nitrogen oxides $\left(\mathrm{NO}_{\mathrm{x}}=\mathrm{NO}_{2}+\mathrm{NO}\right)$, fine particulate matter with a diameter of $2.5 \mu \mathrm{m}$ or less $\left(\mathrm{PM}_{2.5}\right)$, PM coarse with a diameter from 2.5 to $10 \mu \mathrm{m}$ (defined as $\mathrm{PM}_{10}-\mathrm{PM}_{2.5}$ ) and $\mathrm{NH}_{3}$. For use in AQUM the non-methane VOC component of emissions is partitioned into the species required by the RAQ chemical mechanism: formaldehyde, ethene, propene, isoprene, o-xylene, toluene, acetaldehyde, ethane, propane, butane, acetone and methanol (see Table S1 in the Supplement). The inventory total VOC emitted mass is apportioned amongst these species according to the tabulated data for 2006 given by Dore et al. (2008), in a manner which ensures the total VOC mass is accounted for. This same report provides further information that we have used to provide a separate traffic-specific speciation of emitted VOC over the UK.

For gas phase emissions AQUM currently has a simple treatment of the vertical emission profile: all emissions are spread equally over the first four model levels $(20,80,180$ and $320 \mathrm{~m}$ ). This profile was selected on the basis of sensitivity tests under ozone episode conditions. Clearly this is a significant oversimplification, but a more sophisticated treatment is currently being developed (see Sect. 5). However, in practice the representation of a physically realistic profile is limited in an Eulerian model by the spacing of model grid levels and numerical diffusion. Factors representing the monthly, daily and hourly temporal variations are applied to anthropogenic gas phase emissions. The hourly variations, derived from an analysis of traffic cycles, are applied to all species.

The CLASSIC aerosol scheme used by AQUM requires emissions of specific aerosol and gas phase species: FFOC, FFBC, biomass burning aerosol, DMS and sulphur (S) in $\mathrm{SO}_{2}$ for sulphate production, $\mathrm{NO}_{\mathrm{x}}$ and ammonia for nitrate aerosol production, mineral dust and sea salt. The last two species have on-line source terms which depend on meteorology and surface properties. Nitrate aerosol can be regarded as being formed entirely from gas phase precursors (secondary aerosol). Sulphate aerosol is largely secondary, but also contains a small primary component. We currently model the latter by emitting an equivalent amount of gas phase $\mathrm{SO}_{2}$ which is then oxidised to sulphate within CLASSIC. The UK anthropogenic emissions of $\mathrm{SO}_{\mathrm{x}}$ required by CLASSIC are split into high- $(320 \mathrm{~m})$ and low-level (surface) components, representing emissions from chimneys and surface sources, respectively. Volcanic $\mathrm{SO}_{\mathrm{x}}$ emissions are derived from the 3-dimensional climatology of Andres and Kasgnoc (1998). 
Other gas phase emissions for secondary aerosol production are accounted for by the emissions derived from the three inventories described above. However, emissions are required for primary particulate matter. The emissions datasets generated by EMEP, NAEI and ENTEC provide only total PM; thus, in order to use these high-resolution emissions datasets, we must apportion the total PM amongst the different primary species required by CLASSIC. In order to achieve this we have used a dataset compiled by TNO for the GEMS project (Visschedijk et al., 2007). This dataset provides an estimate of the percentage contribution of key aerosol species to the total PM in each SNAP sector. The largest contribution in all sectors of the TNO speciation is "other primary emissions", i.e. non specific PM. Some definite choice must be made about how to apportion this mass amongst the CLASSIC species. We have apportioned both "fine" and "coarse other" primary $\mathrm{PM}_{10}$ to FFBC in the CLASSIC scheme. This choice is somewhat arbitrary and is simply a device to enable all emitted PM to be accounted for. The vertical distribution of aerosol sources are split into high $(320 \mathrm{~m})$ and surface sources of sulphate, black carbon and organic carbon fossil fuel, according to data provided by NAEI.

Several other emissions datasets are used in AQUM. For aircraft emissions, a 2002 dataset taken from the AERO2K project as described in Eyers et al. (2004) is used. Biomass burning emissions of aerosols are taken from year 2000 values from the Global Fire Emissions Database (GFED) version 1 (Randerson et al., 2005). The choice of 2000 emissions is somewhat arbitrary, but these emissions have relatively little impact on our domain. Soil emissions of $\mathrm{NO}_{\mathrm{x}}$ are not included in the current emissions employed by AQUM and have a negligible impact in our domain compared to anthropogenic sources. Biogenic emissions of isoprene are from the monthly climatological data of Poupkou et al. (2010) at $0.125^{\circ} \times 0.0625^{\circ}$ resolution. The use of climatological emissions for biogenic isoprene sources will diminish the ability of the model to respond to increased biogenic ozone precursor emissions during episodes, but this is not expected to be a major factor in the cases analysed in this paper. An interactive biogenic isoprene emission scheme is under development, but is not yet available for use in AQUM.

\subsection{Model configuration for forecast and hindcast studies}

Beginning in April 2010, AQUM was run in the Met Office's operational forecast suite, carrying out a two-day forecast once a day. The model forecast was initialised with meteorological fields from the $0 \mathrm{Z}$ analysis of the NAE model and run for $48 \mathrm{~h}$. The total time taken to run the suite was approximately forty-five minutes including the time to prepare the lateral boundary conditions, which combined meteorology from the NAE with chemistry from the GEMS or MACC global forecasts. The actual forecast component took approximately $30 \mathrm{~min}$ to run using 2 nodes (64 processors) on an
IBM Power 6. This system was used until January 2012, at which point it was upgraded to generate a five-day forecast. In this paper we evaluate the results from the first year of operational forecasts from this system. New updates to Met Office models are introduced at consecutively numbered operational suites (OS). The same scientific configuration was used during all of the first year, during which time three different operational suites were in use: OS24 (1 May 2010-1 November 2010) OS25 (2 November 201015 March 2011) and OS26 (16 March 2011-30 April 2011). Each operational suite version corresponds to a specific model configuration.

To supplement the operational forecasts evaluated here, we have also conducted a case study to examine an additional pollution episode (July 2006). This used a similar set-up to the forecasts, although, due to data availability issues, the initial meteorological analyses were from the global model rather than the NAE. We also examine some episode periods within the year of operational model output in more detail.

\section{Model evaluation methodology}

\subsection{Bias and error metrics}

A wide range of methods and metrics for comparing meteorological forecasts with observed quantities have been developed (see for example Wilks, 2006). Mean error (bias) and root mean square error remain important metrics for estimating forecast errors. However, when verifying chemical species concentration values, some important differences arise compared to verifying standard meteorological fields such as temperature or wind speed. For example, spatial or temporal variations can be much greater and the differences between model and observed values ("model errors") are frequently much larger in magnitude. Under these circumstances it becomes more convenient to work in terms of metrics which can be related to a multiplicative rather than additive error between forecast and observation. Another problem arises when we wish to compare forecast errors for different pollutants: since typical concentrations can vary quite widely between different pollutant types, a given bias or error value can have a quite different significance. It is useful therefore to consider bias and error metrics which are normalised with respect to observed concentrations and hence which can provide a consistent scale regardless of pollutant type. We employ a bias metric termed the "modified normalised mean bias" (MNMB):

$\mathrm{MNMB}=\frac{2}{N} \sum_{i}\left(\frac{f_{i}-o_{i}}{f_{i}+o_{i}}\right)$.

In this equation $f_{i}$ and $o_{i}$ represent the model (forecast) and observed values respectively at site $i$ or at times $i$ for a given site. The use of a normalisation factor of the mean of the observed and forecast value gives a measure of forecast 
bias which performs symmetrically with respect to under and over-prediction and is bounded by the values -2 to +2 . This approach is adopted by Seigneur et.al. (2000), and Cox and Tikvart (1990). It is also useful to understand how the modified normalised mean bias relates to the multiplicative model error. If we define $\alpha_{i}$ as the ratio of forecast to observed value

$f_{i}=\alpha_{i} o_{i}$,

then the mean value of $\alpha$ is given, to a good approximation, by

$\bar{\alpha} \approx \frac{2+\mathrm{MNMB}}{2-\mathrm{MNMB}}$.

Therefore, if the model has a MNMB of +1 , for example, then on average the model predictions are three times the observations, while a MNMB of -0.5 indicates that the forecasts are on average 0.6 times the observations.

Similarly, we use the fractional gross error, FGE, as the indicator of overall forecast error

$\mathrm{FGE}=\frac{2}{N} \sum_{i}\left|\frac{f_{i}-o_{i}}{f_{i}+o_{i}}\right|$

This is essentially a version of the commonly used "mean absolute error", normalised in a manner which performs symmetrically with respect to under and over-prediction and is bounded by the values 0 to +2 . MNMB indicates the extent to which the model systematically under or over-predicts the set of observations, whilst FGE gives a measure of the overall forecast error.

The MNMB and FGE can be combined in a "soccer" plot, which gives a convenient visual representation of the model error characteristics. In these plots (see Fig. 1 for an example) the MNMB is plotted on the x-axis, and FGE on the $y$ axis. Results for each station are plotted as a point. A perfect forecast would appear as a point at the origin, with the magnitude of any discrepancy increasing with distance from this point. Three boxes mark out maximum bias/error combinations of $15 \% / 35 \%, 30 \% / 50 \%$, and $60 \% / 75 \%$ : these values are arbitrary, but have been selected as a convenient guide for visual interpretation of the plots. A systematic bias appears as a linear grouping of points. If other random sources of error dominate, the resulting pattern will be a scatter of points. This representation is a convenient way of presenting the statistics across a range of sites, with the quality of the overall forecast and any strong common characteristics or contrasts between the statistics at rural and urban sites being immediately apparent.

An additional metric for comparing forecast and observation fields is the Pearson correlation coefficient $(R)$. This indicates the extent to which temporal patterns in the forecast match those in the observations at a single site or for an ensemble of sites. Another simple metric we use, which is convenient for giving a broad-scale impression of overall forecast skill, is termed "FAC2". This is the fraction of model

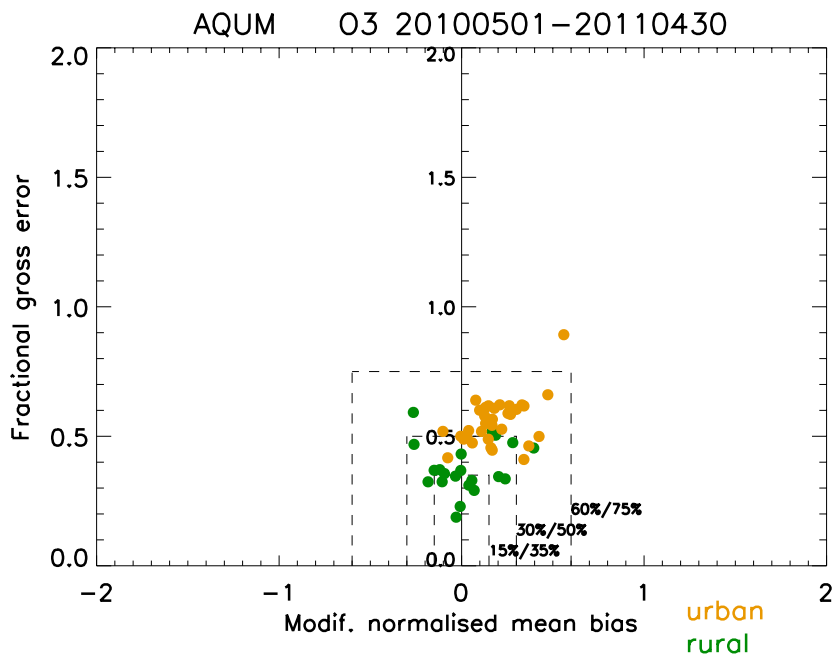

Fig. 1. Soccer plot showing fractional gross error as a function of the modified normalised mean bias relative to hourly observations of ozone for the period 1 May 2010 to 30 April 2011. Urban background and suburban sites are shown in orange, while remote and rural sites are given in green.

predictions where the forecast value is within a factor of 2 (either greater or smaller) of the observed value.

\subsection{Threshold exceedance skill scores}

The verification measures described above provide information about the forecast errors under all conditions, regardless of the magnitude of pollutant concentration. However, it is desirable to have metrics which provide information regarding forecast skill specifically at those times when pollutant levels are elevated and pose a greater risk to human health. It is important to assess the skill that models possess in predicting exceedance of given thresholds. The odds ratio is constructed from a standard $2 \times 2$ contingency table (Stephenson, 2000) and is defined as

$\theta=\frac{a d}{b c}$,

where $a$ is the number of correct forecasts of an event, $b$ is number of false alarms, $c$ is the number of missed forecasts and $d$ is the number of correct rejections.

The odds ratio skill score (ORSS) can be constructed from the odds ratio via a simple transformation

ORSS $=\frac{\theta-1}{\theta+1}$.

This score ranges from -1 to +1 . Forecasts having a strong negative (positive) association with observations have ORSS values tending to $-1(+1)$, whilst random forecasts have ORSS tending to zero. In addition, the hit rate $H$ (the proportion of events occurring which were correctly forecast) and false alarm rate $F$ (the proportion of forecasts of 
Table 1. Prevalence of ozone episode conditions by month between 1 May 2010 and 30 April 2011. For each month, the percentage of hourly average observations (across all sites) where the ozone concentration exceeds the given threshold is shown.

\begin{tabular}{lrrrr}
\hline Month & $\begin{array}{r}\% \text { obs } \\
\geq 80 \mu \mathrm{g} \mathrm{m}^{-3}\end{array}$ & $\begin{array}{r}\% \text { obs } \\
\geq 100 \mu \mathrm{g} \mathrm{m}^{-3}\end{array}$ & $\begin{array}{r}\% \text { obs } \\
\geq 120 \mu \mathrm{g} \mathrm{m}^{-3}\end{array}$ & $\begin{array}{r}\% \text { obs } \\
\geq 150 \mu \mathrm{g} \mathrm{m}^{-3}\end{array}$ \\
\hline May 2010 & 17.767 & 1.825 & 0.184 & 0.008 \\
June & 15.762 & 5.190 & 1.621 & 0.176 \\
July & 3.640 & 0.856 & 0.285 & 0.046 \\
August & 2.414 & 0.396 & 0.061 & 0.027 \\
September & 4.247 & 0.337 & 0.024 & 0.0 \\
October & 1.905 & 0.044 & 0.0 & 0.0 \\
November & 1.59 & 0.0 & 0.0 & 0.0 \\
December & 0.873 & 0.003 & 0.0 & 0.0 \\
January 2011 & 3.509 & 0.038 & 0.013 & 0.005 \\
February & 7.707 & 0.054 & 0.0 & 0.0 \\
March & 11.068 & 0.275 & 0.003 & 0.0 \\
April & 34.785 & 9.248 & 2.790 & 0.356 \\
\hline
\end{tabular}

events occurring which were incorrect forecasts), defined as follows, are valuable metrics for assessing forecast performance:

$$
\begin{aligned}
& H=\frac{a}{a+c} \\
& F=\frac{b}{b+d} .
\end{aligned}
$$

We have used an hourly average ozone concentration of $100 \mu \mathrm{g} \mathrm{m}^{-3}$ as the threshold for defining an event in the categorical analyses conducted in Sect. 4. According to the current UK "Daily Air Quality Index", an 8-h rolling mean value of this magnitude is the threshold for the designation of "moderate" levels of air pollution due to ozone.

Many of the above methods for characterising performance of air quality models were adopted by the GEMS project, based on a report by Agnew et al. (2007), where further discussion of verification issues is given.

\section{Results of model evaluation}

We have evaluated AQUM against hourly observations of $\mathrm{O}_{3}, \mathrm{NO}_{2}, \mathrm{NO}, \mathrm{PM}_{10}$, and $\mathrm{PM}_{2.5}$ from the UK Automatic Urban and Rural (AURN) observing network. Observations from around 70 rural, remote, urban background and suburban sites were used, although not all species are measured at every site. More information about the AURN for 2011 can be found in Stacey (2012), and similar reports for previous years. The periods analysed are the 12-month period 1 May 2010-30 April 2011 and then the poor air quality episodes in July 2006, June 2010 and April 2011. In addition, we have analysed the period June to October 2011 to conduct a comparison of the operational AQUM forecasts with those of the MACC Regional Air Quality Ensemble.

\subsection{Evaluation of one year of operational forecasts}

\subsubsection{Meteorology of May 2010-April 2011}

The 12-month period was characterised by a climatologically average start, followed by a relatively unsettled summer 2010. Autumn started warm and settled, but ended cold, leading into an unusually cold December, followed by an average January, and warm February and spring. The period ended with an exceptional spell of warm, settled weather for the time of year, with April 2011 being the warmest on record in the UK and also one of the sunniest and driest. More details are available from the Met Office monthly weather summaries (Met Office, 2012).

\subsubsection{Ozone}

Ozone production and build up is favoured by strong sunshine, light winds and elevated temperatures, and thus episodes of high ozone concentrations tend to be more frequent and severe in the summer. However, in the Northern Hemisphere the background concentrations are generally highest in the spring (Monks, 2000); this, together with enough insolation (necessary for regional ozone production) during those months, means that spring time ozone episodes are also frequently observed. The meteorology was not generally favourable for ozone production in summer 2010, with cool, unsettled and overcast conditions. In fact, the highest levels of ozone during the period occurred during the exceptionally warm April 2011, which saw around twice the frequency of elevated ozone compared to any other month (Table 1).

Model performance metrics for the forecasts during this 12-month period are shown in Table 2 for ozone (first column). The model has a correlation coefficient with observations of 0.68 , a modest positive bias of $8.38 \mu \mathrm{g} \mathrm{m}^{-3}$, and $77 \%$ of model predictions are within a factor of 2 of 
Table 2. Model performance metrics for the period 1 May 201030 April 2011. These statistics are based on all hourly values in each day. An ozone threshold of $100 \mu \mathrm{g} \mathrm{m}^{-3}$ was used in the calculation of the ORSS, hit rate and false alarm rate metrics. The categorical metrics are presented only for ozone; these metrics add little value for interpreting the results for $\mathrm{NO}_{2}$ and $\mathrm{PM}$ due to the large negative bias in model predictions for these species. The mean and standard deviation (SD) of observations and model values are also shown.

\begin{tabular}{lrrrr}
\hline Metric & $\mathrm{O}_{3}$ & $\mathrm{NO}_{2}$ & $\mathrm{PM}_{10}$ & $\mathrm{PM}_{2.5}$ \\
\hline Correlation & 0.68 & 0.57 & 0.52 & 0.53 \\
Bias $\left(\mu \mathrm{g} \mathrm{m}^{-3}\right)$ & 8.38 & -6.10 & -9.17 & -3.41 \\
RMSE $\left(\mu \mathrm{g} \mathrm{m}^{-3}\right)$ & 22.80 & 18.66 & 17.28 & 12.89 \\
MNMB & 0.12 & -0.26 & -0.67 & -0.30 \\
FGE & 0.49 & 0.69 & 0.83 & 0.62 \\
FAC2 & 0.77 & 0.57 & 0.43 & 0.62 \\
ORSS & 0.95 & $*$ & $*$ & $*$ \\
Hit rate & 0.57 & $*$ & $*$ & $*$ \\
False alarm rate & 0.03 & $*$ & $*$ & $*$ \\
Mean observation $\left(\mu \mathrm{g} \mathrm{m}^{-3}\right)$ & 46.75 & 22.23 & 19.51 & 14.42 \\
Mean model $\left(\mu \mathrm{g} \mathrm{m}^{-3}\right)$ & 55.13 & 16.13 & 10.34 & 11.01 \\
SD observation $\left(\mu \mathrm{g} \mathrm{m}^{-3}\right)$ & 24.84 & 21.29 & 16.79 & 13.61 \\
SD model $\left(\mu \mathrm{g} \mathrm{m}^{-3}\right)$ & 27.58 & 14.41 & 11.94 & 11.86 \\
Number of sites & 55 & 48 & 16 & 23 \\
\hline
\end{tabular}

the observations. The false alarm rate for a threshold of $100 \mu \mathrm{g} \mathrm{m}^{-3}$ is very low at only $3 \%$ and the hit rate is $57 \%$. The soccer plot for ozone at urban background (orange) and rural (green) stations is shown in Fig. 1. At urban stations the model has a positive bias, but there is no clear systematic bias for rural stations. Both bias and other sources of error contribute to the fractional gross error, and both are higher for the urban than the rural stations. These results will be interpreted in the following section in the context of the model's performance for $\mathrm{NO}_{\mathrm{x}}$. In Table 3 we present a summary of the seasonal variation in model performance for ozone predictions. The highest seasonal values of the bias in modelled ozone $\left(\sim 20 \mu \mathrm{g} \mathrm{m}^{-3}\right)$ and of the hit rate for predicting exceedances of the $100 \mu \mathrm{g} \mathrm{m}^{-3}$ ozone threshold (0.84) are found in summer. The high bias observed during that season derives partly from the positive bias in the MACC LBCs (see Sect. 4.3) and partly due to overproduction/insufficient deposition within the model domain. A comparison of the variability in the model predictions (standard deviation of $27.58 \mu \mathrm{g} \mathrm{m}^{-3}$ ) with that of observed values (standard deviation of $24.84 \mu \mathrm{g} \mathrm{m}^{-3}$ ) shows that the model is able to reproduce well the observed variability in ozone concentrations over the course of a year. In Fig. 2 the diurnal variation in bias for ozone is shown. The bias peaks at 05:00 Z, reflecting the poor model skill in capturing the overnight ozone minimum. The main factors for this are likely to be limitations in the current model for representing stable nocturnal boundary layers, night-time chemistry and $\mathrm{NO}_{2}$ concentrations, discussed in the next section.

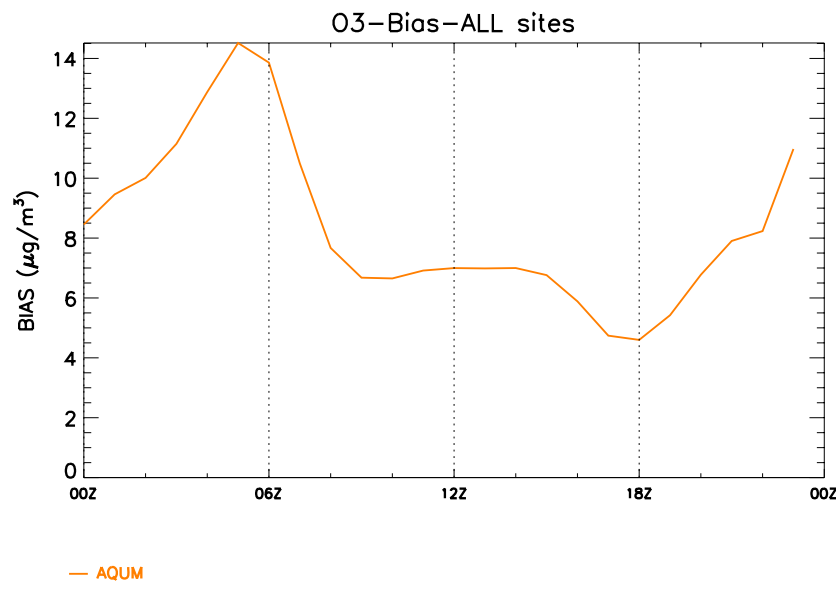

Fig. 2. Hourly variation of the mean ozone bias for the period 1 May 2010 to 30 April 2011.

Table 3. Seasonal variation of model performance metrics for ozone between 1 May 2010 and 30 April 2011. The mean and standard deviation (SD) of observations and model values are also shown.

\begin{tabular}{lrrrr}
\hline Metric & Spring & Summer & Autumn & Winter \\
\hline Correlation & 0.63 & 0.65 & 0.65 & 0.72 \\
Bias $\left(\mu \mathrm{g} \mathrm{m}^{-3}\right)$ & 7.78 & 20.03 & 6.89 & -0.41 \\
RMSE $\left(\mu \mathrm{g} \mathrm{m}^{-3}\right)$ & 24.45 & 26.69 & 20.41 & 19.19 \\
MNMB & 0.13 & 0.38 & 0.12 & -0.12 \\
FGE & 0.41 & 0.42 & 0.50 & 0.61 \\
FAC2 & 0.82 & 0.82 & 0.76 & 0.67 \\
ORSS & 0.86 & 0.97 & 0.99 & 1.00 \\
Hit rate & 0.46 & 0.84 & 0.62 & 0.23 \\
False alarm rate & 0.06 & 0.07 & 0.00 & 0.00 \\
Mean observation $\left(\mu \mathrm{g} \mathrm{m}^{-3}\right)$ & 57.96 & 48.66 & 40.99 & 39.30 \\
Mean model $\left(\mu \mathrm{g} \mathrm{m}^{-3}\right)$ & 65.74 & 68.68 & 47.88 & 38.89 \\
SD observation $\left(\mu \mathrm{g} \mathrm{m}^{-3}\right)$ & 25.55 & 20.84 & 21.82 & 24.86 \\
SD model $\left(\mu \mathrm{g} \mathrm{m}^{-3}\right)$ & 27.11 & 21.06 & 23.78 & 25.96 \\
Number of sites & 55 & 53 & 53 & 54 \\
\hline
\end{tabular}

\subsection{3 $\mathrm{NO}_{2}$}

The model performance metrics for $\mathrm{NO}_{2}$ are also shown in Table 2. The correlation coefficient of 0.57 is lower than for ozone and there is a negative bias of $-6.10 \mu \mathrm{g} \mathrm{m}^{-3}$ which is of a similar magnitude (but opposite in sign) to that of ozone. However, as $\mathrm{NO}_{2}$ concentrations are lower than ozone, the magnitude of the MNMB is much greater, with values of 0.12 for ozone and -0.26 for $\mathrm{NO}_{2}$ (corresponding to $\alpha=1.13$ and 0.77 , respectively).

Figure 3 shows the soccer plot for $\mathrm{NO}_{2}$. There is a large negative bias at urban sites which dominates the overall error at these sites. At rural sites there is generally a positive bias, but the error displays a more random characteristic rather than the systematic trend for urban sites. It should be borne in mind that $\mathrm{NO}_{2}$ measurements made using the chemiluminescence technique with molybdenum converters (as used in the AURN) may overestimate the true concentration by 


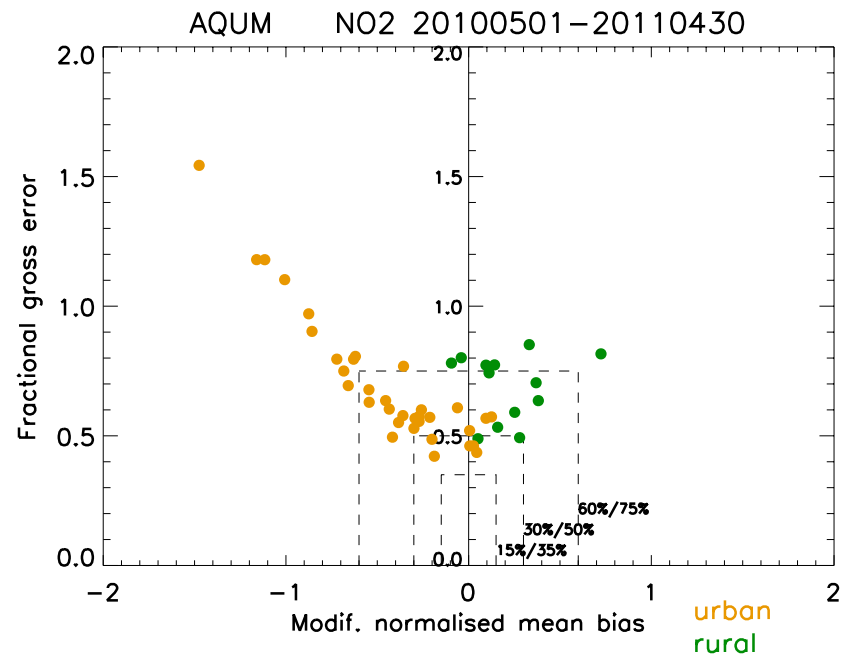

Fig. 3. Soccer plot for $\mathrm{NO}_{2}$ for the period 1 May 2010 to 30 April 2011. Urban background and suburban sites are shown in orange, while remote and rural sites are given in green.

more than $50 \%$, depending on the concentrations of interfering species, the distance from emission sources, and meteorological conditions (e.g. Dunlea et al., 2007; Steinbacher et al., 2007; Lamsal et al., 2008). Considering the lack of longterm simultaneous measurements of $\mathrm{NO}_{2}$ using chemiluminescence analysers equipped with molybdenum and photolytic converters over the UK, and the uncertainties in the correction factors estimated from simulated concentrations of interfering species (see e.g. Lamsal et al., 2008, 2010), no attempt to correct for such interference has been made in this first evaluation of AQUM.

As a regional air quality model at $\sim 12 \mathrm{~km}$ resolution, AQUM does not adequately resolve the sources of primary $\mathrm{NO}$ and $\mathrm{NO}_{2}$ emission (typically dominated by road transport and combustion at point sources). In view of this we have not presented a systematic evaluation of model NO predictions. However, it is worthwhile noting that there is a strong negative bias for NO predictions which dominates the error characteristics. This pattern of over-estimation of $\mathrm{NO}_{\mathrm{x}}$ at rural sites and under-estimation at urban ones is consistent with the model resolution being too coarse to properly resolve sources of $\mathrm{NO}_{\mathrm{x}}$. In an Eulerian model, primary emissions are instantaneously spread over an entire grid box, thus giving apparently lower concentrations close to source regions than occur in reality. Corresponding with this, due to the overall conservation of emitted mass, there is a spurious increase in concentrations at rural locations adjacent to source regions (urban centres or roads). These effects combine to give the pattern of biases observed for primary pollutants at rural and urban sites. This aspect of model performance is likely to improve as model resolution increases. The under-prediction of NO is expected to cause the underestimation of the ozone loss by titration in the model, which

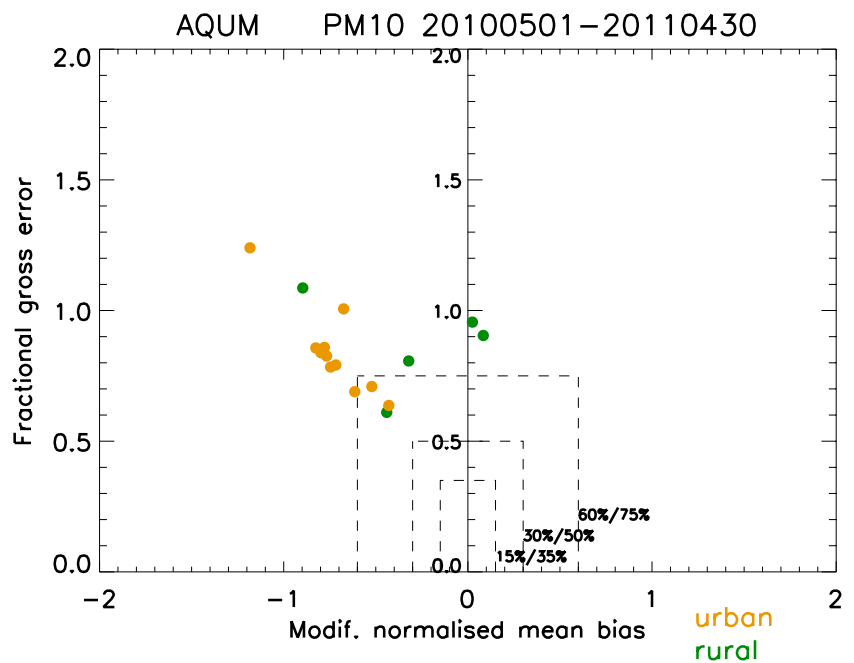

Fig. 4. Soccer plot for $\mathrm{PM}_{10}$ for the period 1 May 2010 to 30 April 2011. Urban background and suburban sites are shown in orange, while remote and rural sites are given in green.

is consistent with the positive bias found for this species at urban sites.

\subsubsection{Particulate matter}

The model performance statistics for $\mathrm{PM}_{10}$ in Table 2 show that overall it is the most challenging pollutant to model accurately. It has the lowest correlation coefficient $(0.52)$ and the greatest negative bias (MNMB $=-0.67$ ), which implies that on average the model predictions for $\mathrm{PM}_{10}$ are only half of the observed concentrations; FGE (0.83) is also the highest of all the pollutants.

Figure 4 shows the soccer plot for $\mathrm{PM}_{10}$. Urban sites consistently have a negative bias and although there are few data available from rural sites, a negative bias is generally exhibited. The under-forecasting of concentrations of particulate matter is a widespread problem in most present-day forecast systems. Inspection of the MACC regional ensemble models (Moinat and Marecal, 2012) shows that all models exhibit a negative bias to some extent.

By contrast, the performance for $\mathrm{PM}_{2.5}$ in AQUM is significantly better, with $\mathrm{MNMB}=-0.30$ and $\mathrm{FGE}=0.62$ (see Table 2). $\mathrm{PM}_{2.5}$ contains both primary and secondary components, with the latter frequently dominating. An example is discussed in Sect. 4.2.3 where speciated PM measurements have allowed a more detailed analysis to be made. This difference in model performance for $\mathrm{PM}_{10}$ and $\mathrm{PM}_{2.5}$ indicates that most of the under-represented $\mathrm{PM}_{10}$ is in the coarse particulate component, from 2.5 to $10 \mu \mathrm{m}$ diameter. Emissions in this size regime are typically due to sea salt, wind-blown dust and matter re-suspended by road transport. These last two components of PM emission depend sensitively on the assumptions made regarding surface properties and are difficult to model accurately. Errors in the representation of physical 


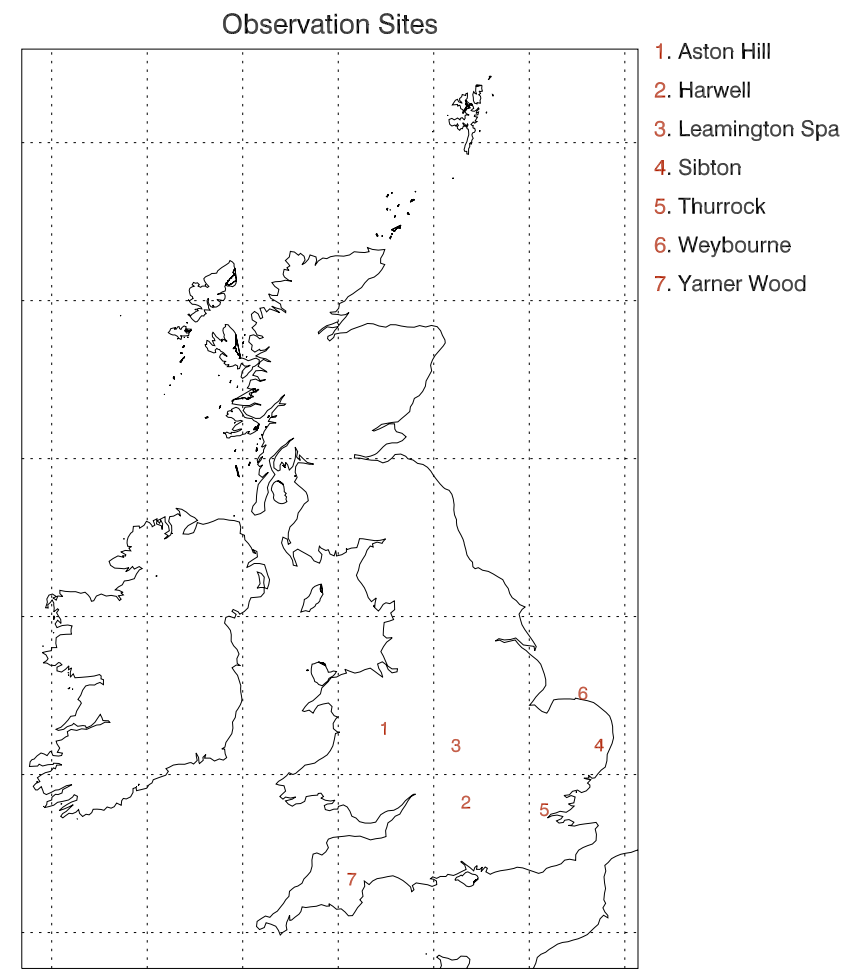

Fig. 5. Location of specific air quality observing sites in the UK referred to in the text and other Figures.

processes in the model which act on particles, such as dry deposition and transport, may also contribute to the errors in modelling $\mathrm{PM}_{10}$.

\subsection{Model evaluation during pollution episodes}

A key requirement of modelling and forecast systems is the ability to represent the rapid rise and fall of pollutant concentrations which occur around episodes of poor air quality. Whilst most models can be tuned to give reasonable monthly or annual averages, a more discriminating test is whether models can respond in episode conditions and demonstrate a wide dynamic range, predicting the onset and termination of elevated pollutant concentrations. To assess this aspect of model performance, it is helpful to compare the variability in model predictions with the variability in observed concentrations for a given pollutant. In the next two sections we assess the performance of the model during periods of moderate and high, ozone and PM: June 2010 and April 2011 as well as the additional month of July 2006, which was modelled in hindcast mode. The geographical locations of particular sites for which we show results are depicted in Fig. 5.

\subsubsection{July 2006}

This month was exceptionally warm and sunny and therefore produced some of the most significant ozone episodes

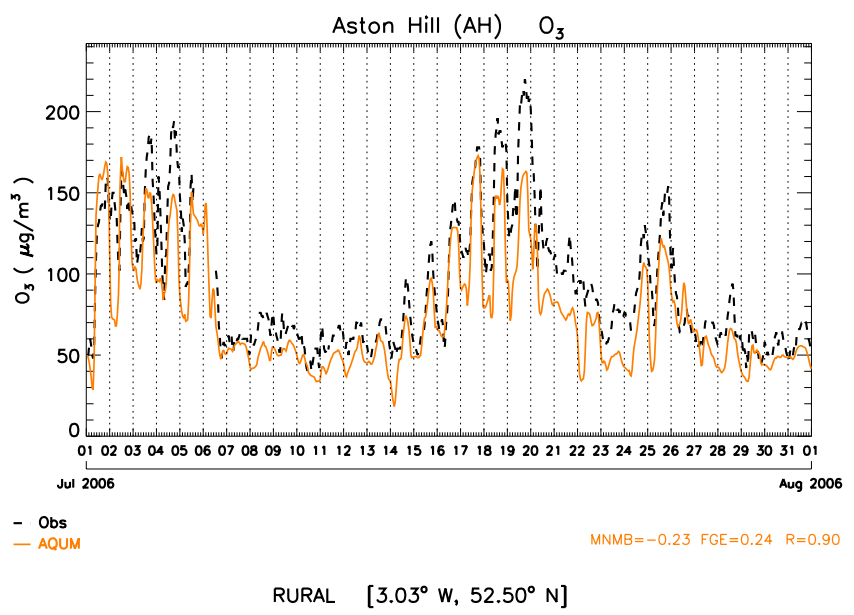

Fig. 6. Time series of hourly ozone concentrations $\left(\mu \mathrm{g} \mathrm{m}^{-3}\right)$ for the rural site at Aston Hill, for July 2006. Observed concentrations are shown as the black dashed line and the model output as the solid orange line.

that the UK has experienced since 2003. Consequently, this month is a demanding test of the model because ozone levels were particularly high at their peak and because the ozone episodes came in separate phases. There were three significant ozone episodes, separated by days when ozone levels were low. This period is therefore a good test of the model's dynamic range in modelling the rapid build-up of ozone, the maintenance of high levels during the episode and the reduction at the end.

Figure 6 shows modelled and observed hourly ozone for Aston Hill, a rural site on the border between England and Wales. At this site there were three ozone episodes: an initial one from the 1 st to the 5th July, a second one from the 17 th to the 20th and a third more modest episode covering 24-25 July. For this site the model exhibits a negative bias, but generally reproduces well the pattern of the observations throughout the month, both in terms of predicting actual ozone levels and episode duration. However, it did not predict the highest concentration occurring on the 19 July. The low values of ozone between the episodes are well reproduced, showing that the model is able to capture abrupt changes in ozone concentration as episode conditions arise and then dissipate. Similar results were found for most rural and urban sites. The summary performance statistics are given in Table 4. Although the bias for this month $\left(1.99 \mathrm{\mu g} \mathrm{m}^{-3}\right)$ is particularly low compared to that of summer 2010 (20.03 $\mu \mathrm{g} \mathrm{m}^{-3}$, see Table 3$)$, the RMSE remains similar. The large difference in the biases is expected to be partly due to the use of chemical LBCs from different sources (global GEMS reanalysis for July 2006 and global MACC forecast for 2010). The model sensitivity to chemical LBCs will be further discussed in Sect. 4.3. 
Table 4. Model performance metrics for ozone for the three case study periods, July 2006, June 2010 and April 2011. An ozone threshold of $100 \mu \mathrm{g} \mathrm{m}^{-3}$ was used in the calculation of the ORSS, hit rate and false alarm rate metrics. The mean and standard deviation (SD) of observations and model values are also shown.

\begin{tabular}{lrrr}
\hline Metric & July 2006 & June 2010 & April 2011 \\
\hline Correlation & 0.75 & 0.66 & 0.59 \\
Bias $\left(\mu \mathrm{g} \mathrm{m}^{-3}\right)$ & 1.99 & 20.37 & 7.09 \\
RMSE $\left(\mu \mathrm{g} \mathrm{m}^{-3}\right)$ & 25.94 & 28.26 & 24.89 \\
MNMB & 0.07 & 0.33 & 0.14 \\
FGE & 0.31 & 0.38 & 0.35 \\
FAC2 & 0.89 & 0.86 & 0.86 \\
ORSS & 0.92 & 0.95 & 0.80 \\
Hit rate & 0.71 & 0.86 & 0.43 \\
False alarm rate & 0.09 & 0.14 & 0.08 \\
Mean observation $\left(\mu \mathrm{g} \mathrm{m}^{-3}\right)$ & 68.94 & 57.17 & 66.66 \\
Mean model $\left(\mu \mathrm{g} \mathrm{m}^{-3}\right)$ & 70.93 & 77.54 & 73.73 \\
SD observation $\left(\mu \mathrm{g} \mathrm{m}^{-3}\right)$ & 38.47 & 23.01 & 28.05 \\
SD model $\left(\mu \mathrm{g} \mathrm{m}^{-3}\right)$ & 33.96 & 24.16 & 23.87 \\
Number of sites & 54 & 53 & 54 \\
\hline
\end{tabular}

A key requirement for a forecast system is to be able to predict ozone concentration levels greater than a given threshold. Using a threshold of $100 \mu \mathrm{g} \mathrm{m}^{-3}$, Table 4 also shows the categorical metrics (hit rate, false alarm rate, ORSS) for July 2006. The hit rate is high for July 2006 (0.71). In view of the fact that there is a low positive bias, this demonstrates that the model predicts this episode well, although the variability in model predictions $\left(33.96 \mu \mathrm{g} \mathrm{m}^{-3}\right)$ is not quite as large as that in observed values $\left(38.47 \mu \mathrm{g} \mathrm{m}^{-3}\right)$. It should also be noted that the hit rate is very sensitive to the threshold chosen and to the overall pollution levels during a given episode, as found in our analysis of April 2011 (see Sect. 4.2.3).

\subsubsection{June 2010}

The weather over the UK in June 2010 was mainly dry and sunny, particularly in the second half when it became very warm, reaching a maximum of $30.9^{\circ} \mathrm{C}$ in Gravesend (South East England) on 27 June. Although sunshine levels were below average in Scotland, they were around $50 \%$ above average in South Wales and South West England, where it was the third sunniest June since 1929. The majority of the rainfall occurred during the second week, and it became unsettled again at the very end of the month (Met Office, 2010).

There were two main poor air quality episodes this month, with high levels of both ozone and $\mathrm{PM}_{10}$. The first period was from 3 to 6 June, during which elevated levels of all the key air quality pollutants were observed across southern England, with ozone reaching a maximum of $172 \mu \mathrm{g} \mathrm{m}^{-3}$ at Weybourne on the 6th. $\mathrm{PM}_{10}$ peaked at $96 \mu \mathrm{g} \mathrm{m}^{-3}$ in Thurrock on the 5th (see Fig. 7). The model captures this first episode well, both in timing and in magnitude. There were other short-lived, smaller magnitude peaks of PM throughout the

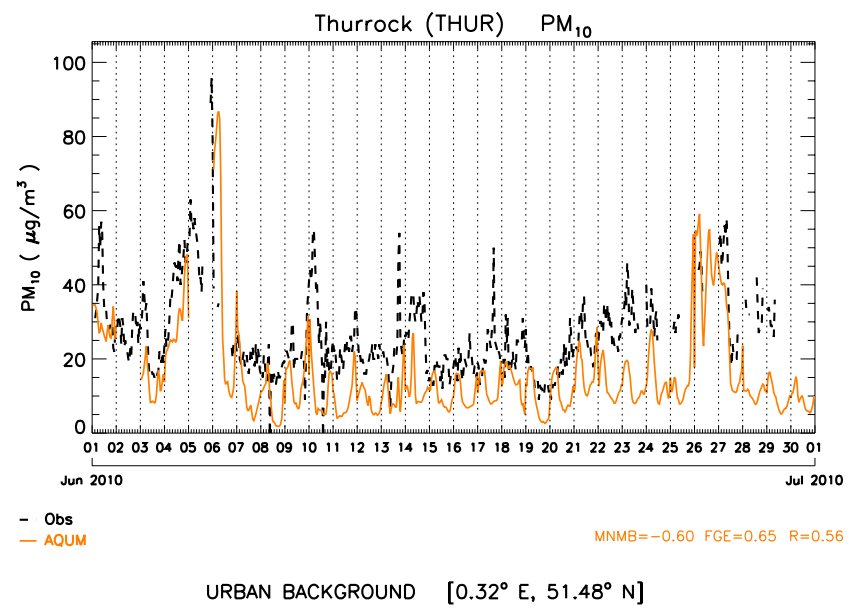

Fig. 7. Time series of hourly $\mathrm{PM}_{10}$ concentrations $\left(\mu \mathrm{g} \mathrm{m}^{-3}\right)$ for the urban background site at Thurrock, east of London, for June 2010. Observed concentrations are shown as the black dashed line and the model output as the solid orange line.

month which the model did not capture so well and overall the model exhibited a negative bias. A determination of the precise reasons for the model's ability to capture some peaks but not others would require a more detailed analysis than is possible at the present time. From 22 to 28 June a longer duration episode occurred. During this episode $\mathrm{PM}_{10}$ reached a maximum of $89 \mu \mathrm{g} \mathrm{m}^{-3}$ in Leamington Spa on the 28th, while a peak value of ozone was recorded in Weybourne on the $27 \mathrm{th}$, at a concentration of $194 \mu \mathrm{g} \mathrm{m}^{-3} ; 40$ other sites observed peak ozone concentrations of above $100 \mu \mathrm{g} \mathrm{m}^{-3}$ and of these, 6 sites measured ozone concentrations higher than $150 \mu \mathrm{g} \mathrm{m}^{-3}$. Figure 8 shows the time series of ozone concentrations for the Harwell site (a rural location around 30 miles west of London) and illustrates the extent of the episode. Here the model captures the general characteristics and higher peak concentrations of the episode well. This is reflected in the high ORSS score of 0.95 . The ozone prediction performance statistics for the whole month are shown in Table 4. For the month overall, the variability in model predictions $\left(24.16 \mu \mathrm{g} \mathrm{m}^{-3}\right)$ slightly exceeds that in observed values $\left(23.01 \mu \mathrm{g} \mathrm{m}^{-3}\right)$.

A contour plot showing the daily maximum values of ozone across the model domain is shown for 27 June in Fig. 9. In this figure the observed daily maxima are overplotted as colour-coded squares. It can be seen that the model predicts ozone levels higher than $150 \mu \mathrm{g} \mathrm{m}^{-3}$ across a large swathe of south-eastern England, compared to observed concentrations, where only two sites - Weybourne and Sibton - actually reached these levels. This trend to overforecast ozone levels is continued across the entire month, as indicated by the relatively large positive model bias of $20.37 \mu \mathrm{g} \mathrm{m}^{-3}$ (see Table 4) for the thirty day period. This also results in a high hit rate of 0.86 and a false alarm rate somewhat higher than for other episodes (0.14). 


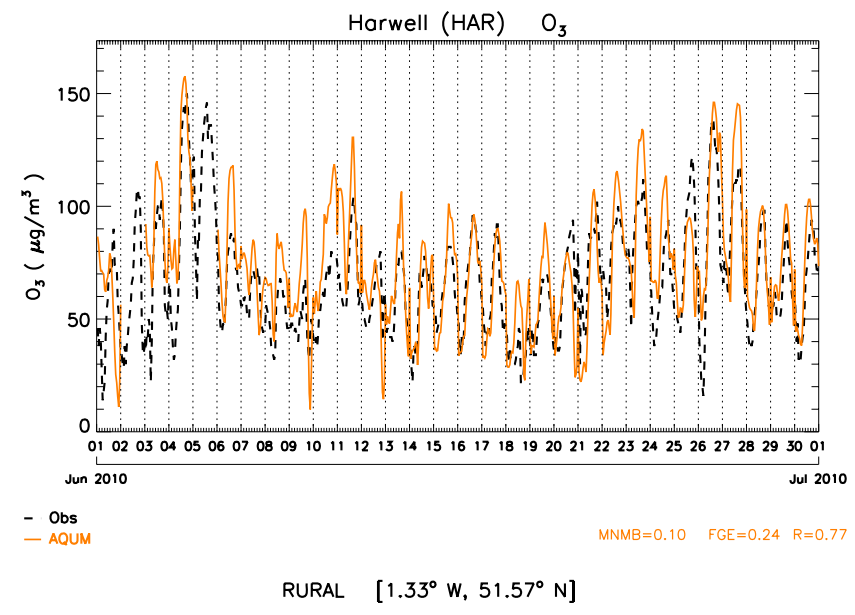

Fig. 8. Time series of hourly ozone concentrations $\left(\mu \mathrm{g} \mathrm{m}^{-3}\right)$ for the rural site Harwell for June 2010. Observed concentrations are shown as the black dashed line and the model output as the solid orange line.

\subsubsection{April 2011}

The meteorology of May 2010-April 2011 was not generally conducive to the build-up of ozone, with the summer lacking extended periods of clear skies and high temperatures. Instead, a period of elevated ozone occurred during April 2011, which was unusually warm and sunny. The combination of these conditions with the elevated background concentrations noted above resulted in some of the poorest air quality over the UK for the whole of 2011. The elevated ozone levels occurred together with a major PM episode. Meteorologically, high pressure dominated the UK weather throughout the month, resulting in mainly fine, warm weather. Daily maximum temperatures were well above normal - by as much as $6^{\circ} \mathrm{C}$ in South East England, with a maximum of $27.8^{\circ} \mathrm{C}$ recorded in Wisley, Surrey, on 23 April. It was also one of the driest and sunniest months of April on record, although Scotland had near to above normal rainfall (Met Office, 2011).

There were widespread elevated ozone levels which peaked during the period 20th-23rd. Due to the contribution of background ozone levels the onset of the episode is not especially pronounced, as demonstrated by the time series for Harwell shown in Fig. 10, where ozone levels were generally high throughout the month. Table 4 shows the model performance characteristics for April 2011 for ozone. While the bias and RMSE are generally comparable to the other episodes, the hit rate is significantly lower. This is likely to be because the ozone concentrations were close to the threshold value for much of April, so that small errors in the model forecast concentration values could often result in incorrect classification as a hit or false alarm.

The most notable feature for April 2011 was the major PM episode which occurred from approximately 18 to 23 April
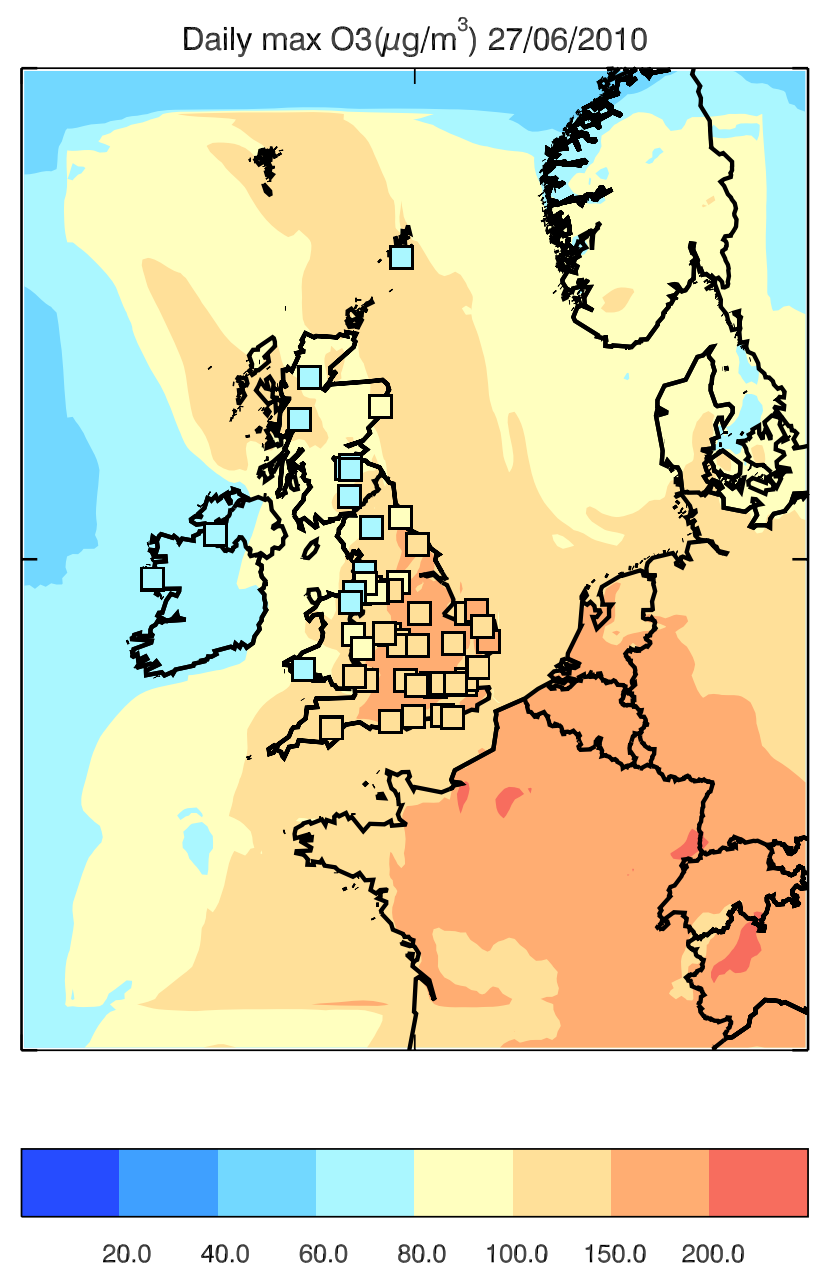

Fig. 9. Maximum modelled hourly ozone concentrations $\left(\mu \mathrm{g} \mathrm{m}^{-3}\right)$ for 27 June 2010, with observed concentrations over-plotted within squares.

and affected the whole of the UK. A maximum $\mathrm{PM}_{10}$ concentration of $142 \mu \mathrm{g} \mathrm{m}^{-3}$ was observed in Thurrock on 21 April (see Fig. 11). AQUM predicts the overall evolution of the episode well, but under-predicts the observed concentrations on the three days which saw the maximum $\mathrm{PM}_{10}$ levels. This episode illustrates that when $\mathrm{PM}_{10}$ is dominated by the formation of $\mathrm{PM}_{2.5}$ secondary aerosol, AQUM predictions of the former improve. Speciated PM observations are available for this episode at the rural Harwell site (S. Telling, personal communication, 2011). A time series plot of measured $\mathrm{PM}_{2.5}$ and its components at this site is shown in Fig. 12. On 22 April $\mathrm{PM}_{10}$ at Harwell reached a maximum concentration of $105 \mu \mathrm{g} \mathrm{m}^{-3}$; most of this was in the $\mathrm{PM}_{2.5}$ component with a concentration of $98 \mu \mathrm{g} \mathrm{m}^{-3}$. The largest component of $\mathrm{PM}_{2.5}$ was nitrate aerosol, with a peak concentration of $56 \mu \mathrm{g} \mathrm{m}^{-3}$. The modelled speciated $\mathrm{PM}_{2.5}$ concentrations are shown in Fig. 13 for comparison with the observations. AQUM correctly predicts the overall magnitude of $\mathrm{PM}_{2.5}$ and the relative contributions of nitrate, ammonium and sulphate 


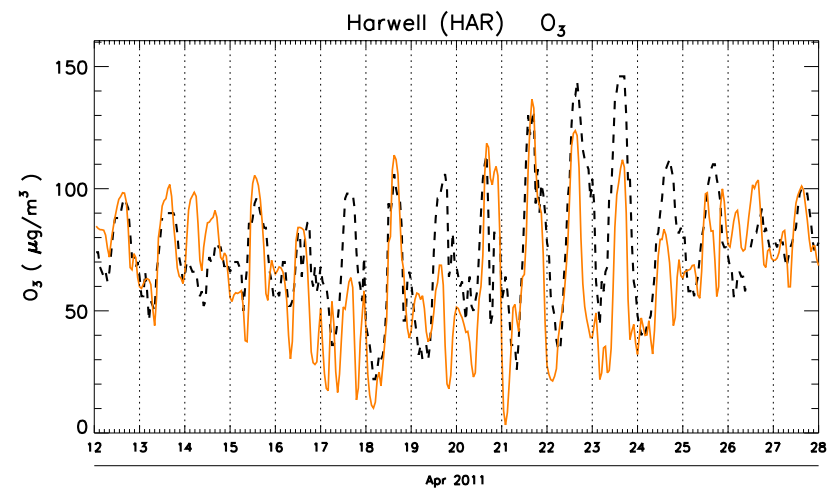

- Obs
- AQUM

RURAL $\quad\left[1.33^{\circ} \mathrm{W}, 51.57^{\circ} \mathrm{N}\right]$

Fig. 10. Time series of hourly ozone concentrations $\left(\mu \mathrm{g} \mathrm{m}^{-3}\right)$ for the rural site at Harwell, for April 2011. Observed concentrations are shown as the black dashed line and the model output as the solid orange line.

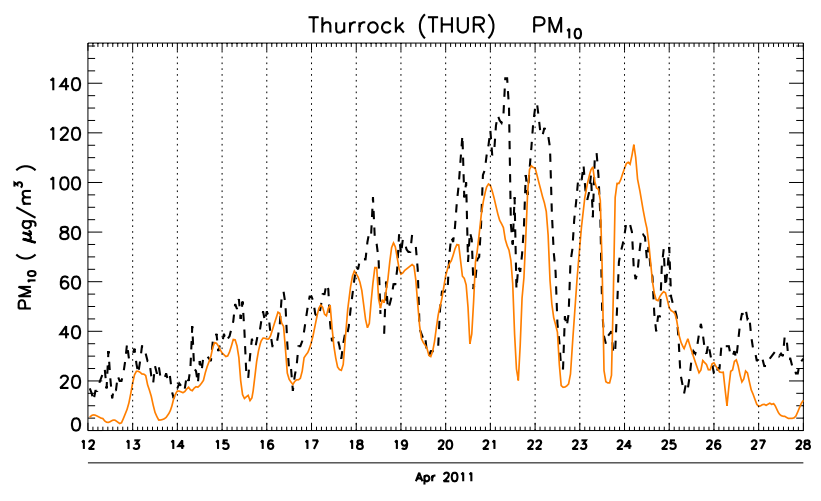

- Obs
- AQUM

$M N M B=-0.33 \quad F G E=0.43 \quad R=0.84$

URBAN BACKGROUND $\left[0.32^{\circ} \mathrm{E}, 51.48^{\circ} \mathrm{N}\right]$

Fig. 11. Time series of hourly $\mathrm{PM}_{10}$ concentrations $\left(\mu \mathrm{g} \mathrm{m}^{-3}\right)$ for the urban background site of Thurrock, east of London at the peak of the April 2011 episode. Observed concentrations are shown as the black dashed line and the model output as the solid orange line.

aerosol components. However, the model does not predict the worsening of $\mathrm{PM}_{2.5}$ values from the 20th to the 22nd and significantly over-predicts values on 23rd April and other days.

\subsection{Sensitivity to chemical LBCs}

AQUM has a relatively small domain, hence model predictions can be expected to exhibit sensitivity to the chemical LBCs. We have assessed this sensitivity of model ozone predictions in two ways: (i) by running AQUM with two independent LBC datasets and (ii) by adding an intermediate European nested domain and evaluating the changes in AQUM performance.

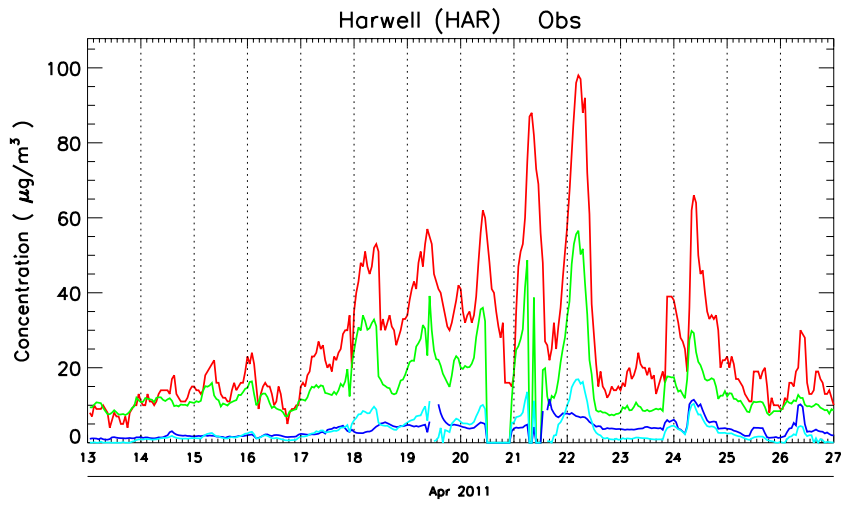

$-\mathrm{PM}_{2.5}$
$-\mathrm{PM}_{2.5} \mathrm{NO}_{5}{ }^{-}$
$-\mathrm{PM}_{2.5} \mathrm{SO}_{4}{ }^{2-}$

$=\mathrm{PM}_{2.5}-\mathrm{SO}_{4}{ }^{2-}$

RURAL $\quad\left[1.33^{\circ} \mathrm{W}, 51.57^{\circ} \mathrm{N}\right]$

Fig. 12. Speciated $\mathrm{PM}_{2.5}$ measurements at the rural site Harwell for the peak of the April 2011 episode.

\subsubsection{Model comparison using independent LBC datasets}

Both the GEMS and MACC projects produced global model chemical reanalyses. These reanalyses were conducted with different model configurations and resulted in two independent datasets which were used to derive chemical LBCs for AQUM. The model was re-run for the whole of 2006 using both sets of LBCs. An example time series of hourly ozone predictions at the rural Yarner Wood station is shown in Fig. 14. From January to May simulations made with the GEMS LBCs exhibit a larger negative bias than those made with the MACC LBCs; from May to the end of the year runs using the GEMS LBCs generally perform better, with a smaller positive bias. Plots for other sites show the same general behaviour. These results are consistent with the known negative bias in lower tropospheric ozone from the GEMS reanalysis during the first quarter of 2006 (Schere et al., 2012) and illustrate the sensitivity of AQUM predictions to the LBCs used. The question then arises as to whether this sensitivity can be reduced by using an intermediate nest on a larger domain.

\subsubsection{Impact of intermediate nest}

A version of AQUM with a resolution of approximately $18 \mathrm{~km}$ was constructed on the intermediate, European domain shown in Fig. 15. This model was set up to use LBCs from the GEMS/MACC global models and then provide LBCs to the standard AQUM domain. With this additional configuration it was possible to analyse a further 4 model configurations in addition to the two described in the previous section, giving the following six run combinations altogether: 


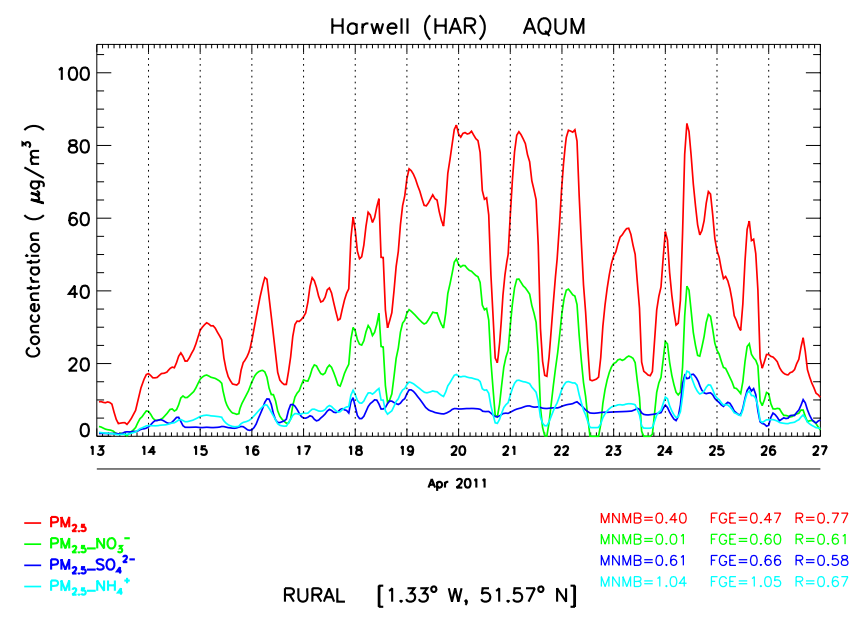

Fig. 13. Speciated $\mathrm{PM}_{2.5}$ model forecasts for the rural site Harwell for the peak of the April 2011 episode.

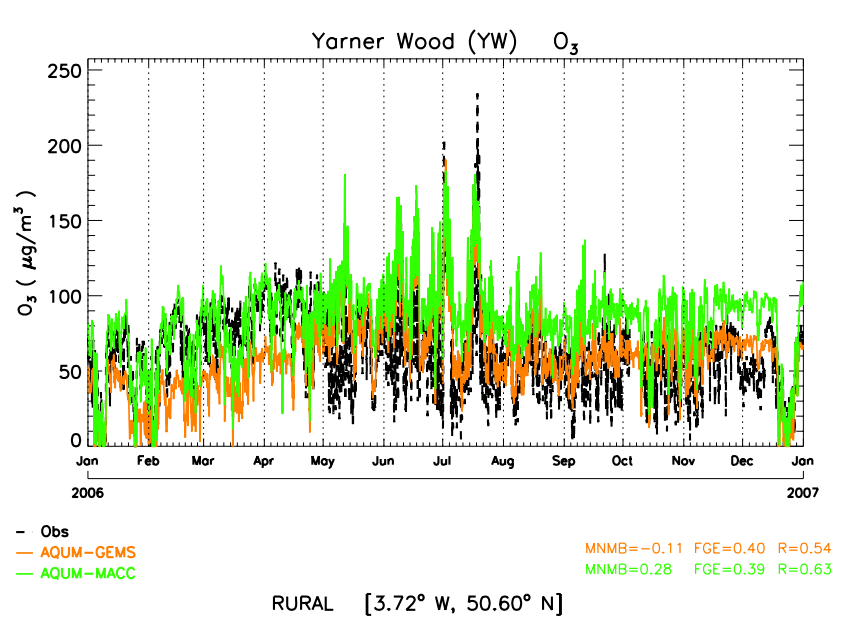

Fig. 14. Comparison of a year-long run of AQUM for 2006: results for ozone at the rural site Yarner Wood using LBCs from GEMS (orange) and MACC (green) reanalyses.

- AQUM-GEMS and AQUM-MACC: these refer to the standard domain of AQUM driven with either GEMS or MACC global model LBCs.

- EU-GEMS and EU-MACC: these refer to the European domain driven with either GEMS or MACC global model LBCs.

- EUUK-GEMS and EUUK-MACC: these refer to the 3level nested configuration of the standard AQUM domain driven by LBCs from the European domain, which is in turn driven with either GEMS or MACC global model LBCs.

These additional model configurations were run for June and July 2012. Figure 16 shows a time series at the Harwell site for AQUM-GEMS, EU-GEMS and EUUK-GEMS.

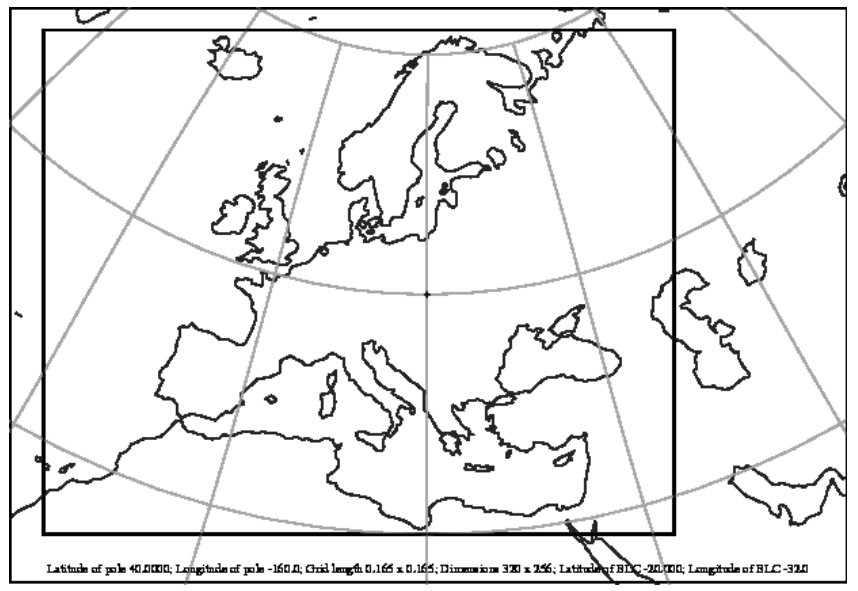

Fig. 15. Location of the intermediate European domain used to evaluate sensitivity to LBCs.

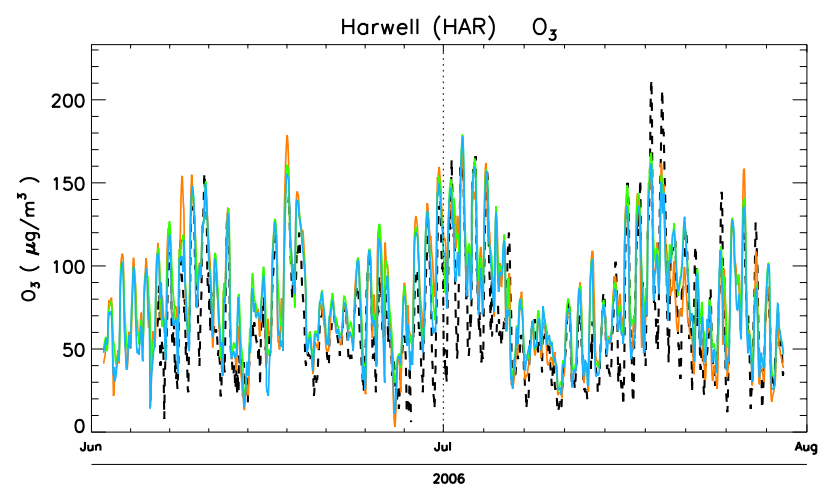

- Obs
- AQUM-GEMS
- EU-GEMS
- EUUK-GEMS

RURAL $\quad\left[1.33^{\circ} \mathrm{W}, 51.57^{\circ} \mathrm{N}\right]$

$M N M B=0.17 \quad F G E=0.29 \quad R=0.8$

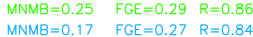

Fig. 16. Time series of ozone at the rural site Harwell comparing AQUM-GEMS, EU-GEMS and EUUK-GEMS model configurations for 2 June to 29 July 2006.

The three configurations produce quite similar results. The use of LBCs from MACC instead of from GEMS yields a very similar outcome (not shown). Overall, there appears to be no benefit from the intermediate European domain during this period. Table 5 shows summary statistics for these three simulations, which confirms this statement. The FGE is very similar in all cases, whilst the hit rate is degraded somewhat by the addition of the intermediate nest. We conclude that the addition of an intermediate, nested European domain adds little value to the overall performance of the system for UK forecasts. Furthermore, these results show that for relatively long-lived pollutants such as ozone, the LBCs remain an important source of model sensitivity. 
Table 5. Model performance metrics for ozone for the three model configurations AQUM-GEMS, EU-GEMS, EUUK-GEMS for the period 2 June to 29 July 2006.

\begin{tabular}{lrrr}
\hline Metric & $\begin{array}{r}\text { AQUM- } \\
\text { GEMS }\end{array}$ & $\begin{array}{r}\text { EU- } \\
\text { GEMS }\end{array}$ & $\begin{array}{r}\text { EUUK- } \\
\text { GEMS }\end{array}$ \\
\hline Correlation & 0.72 & 0.75 & 0.74 \\
Bias $\left(\mu \mathrm{g} \mathrm{m}^{-3}\right)$ & 11.40 & 12.09 & 8.48 \\
RMSE $\left(\mu \mathrm{g} \mathrm{m}^{-3}\right)$ & 27.57 & 26.51 & 25.14 \\
MNMB & 0.21 & 0.24 & 0.19 \\
FGE & 0.33 & 0.33 & 0.31 \\
FAC2 & 0.88 & 0.87 & 0.88 \\
ORSS & 0.92 & 0.92 & 0.92 \\
Hit rate & 0.80 & 0.78 & 0.74 \\
False alarm rate & 0.15 & 0.13 & 0.10 \\
Mean observation $\left(\mu \mathrm{g} \mathrm{m}^{-3}\right)$ & 67.96 & 67.96 & 67.96 \\
Mean model $\left(\mu \mathrm{g} \mathrm{m}^{-3}\right)$ & 79.36 & 80.04 & 76.44 \\
SD observation $\left(\mu \mathrm{g} \mathrm{m}^{-3}\right)$ & 35.32 & 35.32 & 35.32 \\
SD model $\left(\mu \mathrm{g} \mathrm{m}^{-3}\right)$ & 31.78 & 27.86 & 28.37 \\
Number of sites $^{-3}$ & 59 & 59 & 59 \\
\hline
\end{tabular}

\subsection{Comparison with the MACC regional air quality ensemble}

MACC was a project funded under the European Union Seventh Framework Programme FP7 to develop and implement trial elements of an atmospheric composition and climate service. One element of MACC is a European air quality forecast service. Seven different models forecasting for a European domain contribute to an ensemble median forecast out to three days ahead. In order to place the performance of AQUM in the context of other similar air quality forecast models we have conducted a comparison between AQUM and the MACC ensemble forecast over the period June to October 2011.

Summer 2011 was generally cooler and slightly wetter than average, and in particular it was wetter than 2010. However, there were some periods of fine weather, and the last few days of September and the first week in October were very warm and sunny for this time of year. There were several periods of elevated ozone during June-October: in both early and late July as well as at the end of September and early October. Both AQUM and the MACC ensemble captured these events fairly well (see, for example, a time series of ozone daily maximum at Harwell in Fig. 17). The times series plot in Fig. 18 compares the hourly ozone concentration bias for the MACC ensemble and AQUM. In general, AQUM has a higher bias than the MACC ensemble, with mean values over the whole period of $13.28 \mu \mathrm{g} \mathrm{m}^{-3}$ for AQUM compared to $4.10 \mu \mathrm{g} \mathrm{m}^{-3}$ for the MACC ensemble. This figure illustrates that the positive bias of both model systems rises during the episode periods. Table 6 shows a summary of performance metrics. The performance of the MACC ensemble is somewhat better than that of AQUM for most metrics, but AQUM

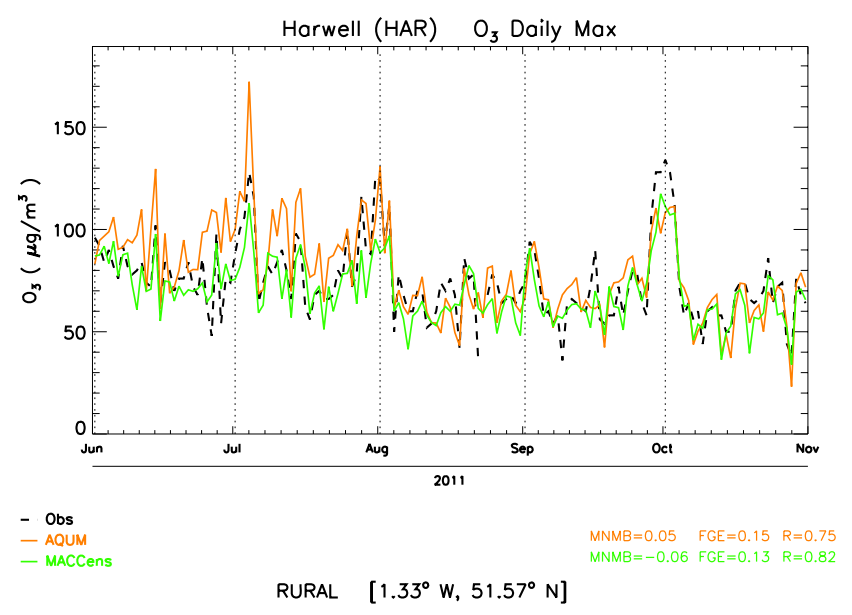

Fig. 17. AQUM and MACC ensemble predictions of daily maximum ozone concentrations compared to observations at the rural site Harwell for 1 June to 31 October 2011. The observations are the black dashed line, AQUM output in orange and MACC ensemble predictions in green.

has a notably higher hit rate (for the $100 \mu \mathrm{g} \mathrm{m}^{-3}$ ozone concentration threshold) and a range of variability (given by the standard deviation) closer to that of the observations. Considering mean value metrics such as bias and RMSE, one would expect the ensemble performance of a collection of wellconfigured models to be better than that of any single member, hence the greater skill of the ensemble forecast as indicated by these metrics is not surprising. However, the hit rate of AQUM at 0.64 is significantly better than the value of 0.27 achieved by the MACC ensemble. The contributing factors for this difference are likely to be (i) the "smoothing" effect of taking the median value of the MACC ensemble, which excludes the higher magnitude forecasts and (ii) the higher bias of AQUM. For a forecast model designed for issuing health impact warnings, the higher hit rate is arguably a more important characteristic than a lower bias, as long as the false alarm rate does not increase unacceptably as a result. The false alarm rate for AQUM is only $4 \%$, whilst the MACC ensemble has no false alarms. Finally, the lower range of variability in the MACC ensemble $\left(\sim 17.6 \mu \mathrm{g} \mathrm{m}^{-3}\right.$ standard deviation) compared to the AQUM forecast $\left(\sim 21.3 \mu \mathrm{g} \mathrm{m}^{-3}\right)$ and the observations $\left(\sim 21.0 \mu \mathrm{g} \mathrm{m}^{-3}\right)$ might also be related to the "smoothing" effect of the ensemble.

\subsection{Variation of model skill with forecast lead time}

A further area where we have evaluated AQUM is to examine the variation of skill with forecast lead time. AQUM operational forecasts extend out to two days, thus it is possible to compare forecasts made two days ahead with those made one day ahead. We have analysed AQUM day 1 and day 2 ozone forecasts over the period May 2010 to April 2011 and the results are presented in Table 7. In contrast to meteorological 


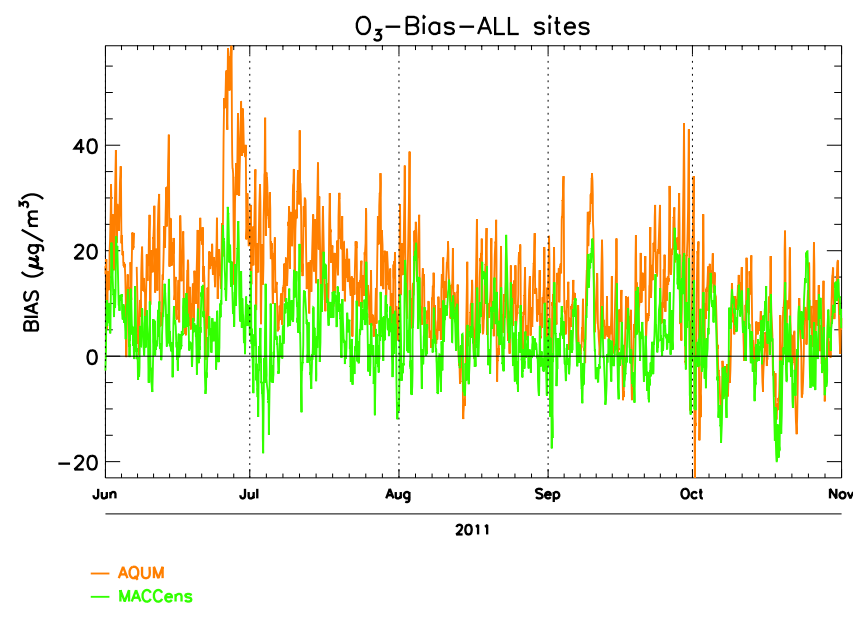

Fig. 18. Time series of hourly ozone bias for AQUM operational output in orange and MACC ensemble in green.

Table 6. Performance metrics for AQUM and MACC ensemble ozone forecasts for the period 1 June to 31 October 2011. The small differences in the means and standard deviations of the observations used for evaluating AQUM and the MACC ensemble are due to minor variations in data availability over the period.

\begin{tabular}{|c|c|c|}
\hline Metric & AQUM & MACC Ensemble \\
\hline Correlation & 0.62 & 0.71 \\
\hline $\operatorname{Bias}\left(\mu \mathrm{g} \mathrm{m}^{-3}\right)$ & 13.28 & 4.10 \\
\hline $\operatorname{RMSE}\left(\mu \mathrm{g} \mathrm{m}^{-3}\right)$ & 22.66 & 15.71 \\
\hline FAC2 & 0.85 & 0.89 \\
\hline ORSS & 0.96 & 0.99 \\
\hline Hit rate & 0.64 & 0.27 \\
\hline False alarm rate & 0.04 & 0.0 \\
\hline Mean observation $\left(\mu \mathrm{g} \mathrm{m}^{-3}\right)$ & 44.71 & 47.75 \\
\hline Mean model $\left(\mu \mathrm{g} \mathrm{m}^{-3}\right)$ & 60.99 & 51.85 \\
\hline SD observation $\left(\mu \mathrm{g} \mathrm{m}^{-3}\right)$ & 21.04 & 21.09 \\
\hline $\mathrm{SD}$ model $\left(\mu \mathrm{g} \mathrm{m}^{-3}\right)$ & 21.29 & 17.55 \\
\hline Number of sites & 60 & 60 \\
\hline
\end{tabular}

variables, where one generally finds a significant decrease in forecast skill with lead time, ozone forecasts exhibit a weak dependence on lead time for all metrics. This is consistent with our general observation that, for air quality forecasting, a 24-h persistence forecast (i.e. assuming the next day has the same air quality as the current day) usually exhibits a substantial level of skill. The contrasting behaviour with meteorological forecasts indicates that the factors controlling errors differ in the two types of forecast, and that the impact of typical errors in meteorology does not dominate other sources of error in ozone forecasts, such as emissions or the representation of atmospheric chemistry.
Table 7. AQUM performance metrics for ozone forecasts over the period 1 May 2010 to 30 April 2011, illustrating variation with forecast lead time. The small differences in the means and standard deviations of the observations used for evaluating forecasts are due to minor variations in data availability over the period.

\begin{tabular}{lrr}
\hline Metric & Day 1 & Day 2 \\
\hline Correlation & 0.68 & 0.66 \\
Bias $\left(\mu \mathrm{g} \mathrm{m}^{-3}\right)$ & 8.38 & 9.04 \\
RMSE $\left(\mu \mathrm{g} \mathrm{m}^{-3}\right)$ & 22.80 & 23.79 \\
FAC2 & 0.77 & 0.76 \\
ORSS & 0.95 & 0.95 \\
Hit rate & 0.57 & 0.56 \\
False alarm rate & 0.03 & 0.04 \\
Mean observation $\left(\mu \mathrm{g} \mathrm{m}^{-3}\right)$ & 46.75 & 46.77 \\
Mean model $\left(\mu \mathrm{g} \mathrm{m}^{-3}\right)$ & 55.13 & 55.81 \\
SD observation $\left(\mu \mathrm{g} \mathrm{m}^{-3}\right)$ & 24.84 & 24.94 \\
SD model $\left(\mu \mathrm{g} \mathrm{m}^{-3}\right)$ & 27.58 & 27.70 \\
Number of sites & 55 & 55 \\
\hline
\end{tabular}

\section{Summary and future developments}

We have presented a description of a new on-line air quality model AQUM, which is based on the Met Office Unified Model and uses the UKCA sub-model for describing atmospheric chemistry processes. A variety of metrics for assessing model performance have been described and the importance of using metrics which assess both mean performance and skill in predicting exceedance of threshold concentration values is emphasised. We have evaluated AQUM against routine, hourly observations from the UK AURN surface observing network. Averaged over the course of a full year, the model exhibits a positive bias for ozone of around $8 \mu \mathrm{g} \mathrm{m}^{-3}$. The model exhibits good dynamic range in simulating ozone, as shown by the fact that the variability in model predictions over the course of a year is comparable to, or exceeds, the variability in observed values. Case studies of elevated ozone episodes demonstrate that the model reproduces time series of measured ozone concentrations at individual sites well. For $\mathrm{NO}_{2}$ the model exhibits a negative bias for urban sites and positive bias for rural sites. This is likely to be a consequence of the fact that, at $12-\mathrm{km}$ resolution, AQUM does not adequately resolve the main sources of $\mathrm{NO}_{\mathrm{x}}$ (i.e. road traffic and combustion point sources). This results in the dilution of emissions close to source regions (urban areas) and enhanced emissions in regions distant from sources (rural areas). For $\mathrm{PM}_{10}$ the model generally exhibits a negative bias (as discussed in Sect. 4.1.4.), in common with many air quality models. However, the model performance for $\mathrm{PM}_{2.5}$ is better, with a much smaller negative bias. During particular PM episodes where secondary inorganic aerosols dominate, such as April 2011, $\mathrm{PM}_{10}$ performance improves. The lower skill exhibited for $\mathrm{PM}_{10}$ is likely to be the result of missing coarse component emissions which are not represented 
in the annual average inventories, such as re-suspension of deposited coarse PM, sea salt or wind blown dust.

The sensitivity of modelled ozone to chemical LBCs has been assessed by taking these from two different global reanalyses and by comparing the standard, single-nested configuration with another configuration having an intermediate European nest. We conclude that, even with a much larger regional domain, the LBCs remain an important source of model error for relatively long-lived pollutants such as ozone. The AQUM forecast for ozone has also been compared to the median of the MACC ensemble and overall the latter exhibits better performance as judged by mean field metrics. However, it has a significantly lower hit rate for predicting exceedance of the $100 \mu \mathrm{g} \mathrm{m}^{-3}$ ozone concentration threshold and somewhat lower variability compared to that of AQUM and the observations.

AQUM is being actively developed by the Met Office and UKCA academic partners. Priority areas for future developments include:

i. An improved representation of emissions. At present, monthly data from three emission inventories (EMEP, NAEI and ENTEC) are interpolated to the AQUM horizontal grid and merged. These data, which originate from different source sectors, are aggregated as a single surface emission field for most species. In the case of gas phase emissions, such 2-dimensional fields have been spread over the four lowest model levels in this study. Temporal factors accounting for day of week and hour of the day have also been applied based on UK data. A more comprehensive system is currently being developed which will enable separate vertical and temporal profiles to be applied according to source sectors. Different options are being considered for the allocation of emissions in the model layers such as the use of vertical profiles according to a default distribution based on SNAP sectors (Vidic, 2002) or effective emission heights calculated by more recent studies (e.g. Pregger and Friedrich, 2009; Bieser et al., 2011). Our current time profiles will also be evaluated against new temporal emission factors (e.g. Menut et al., 2012) and updated if needed. Finally, recent developments in UKCA will enable the use of interactive emissions of biogenic VOCs. The new framework will also allow us to more easily interface new or improved treatments of biomass burning and soil emissions.

ii. Replacement of the mass-based CLASSIC aerosol scheme by the modal aerosol microphysics scheme "UKCA-GLOMAP-mode" (Mann et al., 2010). This more sophisticated scheme will allow the time evolution of aerosol modes, the separate modelling of aerosol mass and number, the representation of internally mixed particles, the inclusion of microphysical processes such as nucleation, a better coupling with UKCA oxidants, and an improved representation of sea salt and prognostic secondary organic aerosols. Currently, the fact that the CLASSIC aerosol scheme treats the sulphur chemistry in a separate module to the rest of the gas phase chemistry also makes it difficult to treat from the emissions perspective and introduces the potential for inconsistencies in the chemical mechanism; this will be overcome with the use of the more consistent UKCA-GLOMAP-mode scheme in which the sulphur chemistry is an intrinsic part of the chemical mechanism and emissions of all gases and aerosols are dealt with in the same framework. The analysis of global model simulations using both schemes shows that UKCA-GLOMAP-mode compares better than CLASSIC against a global aerosol reanalysis and aerosol ground-based observations (Bellouin et al., 2012).

iii. The implementation of a post-processing system to apply a bias correction to forecasts. The observation that a 24-h persistence forecast for air quality generally displays considerable skill suggests that measured values from the previous 24-h period can be used to derive a bias correction to new forecasts. We have begun development work to explore the potential of this and initial results appear promising.

iv. A final priority for development is to increase the model resolution. The Met Office currently runs a $1.5-\mathrm{km}$ resolution, 70-level meteorological model which resolves smaller scale convection and gives an improved forecast for precipitation. In the near future we plan to develop a version of AQUM at 4-km resolution, reducing ultimately to $1.5 \mathrm{~km}$ in line with the meteorological forecast model. In addition to providing improvements in the meteorological parameters in AQUM, this will allow an improved representation of concentration gradients in pollutants, giving higher concentrations of primary pollutants in urban areas and lower values in the rural areas close to cities.

\section{Supplementary material related to this article is available online at: http://www.geosci-model-dev.net/6/ 353/2013/gmd-6-353-2013-supplement.pdf.}

\section{Copyright Statement}

The works published in this journal are distributed under the Creative Commons Attribution 3.0 License. This license does not affect the Crown copyright work, which is re-usable under the Open Government Licence (OGL). The Creative Commons Attribution 3.0 License and the OGL are interoperable and do not conflict with, reduce or limit each other.

(C) Crown copyright 2013 
Acknowledgements. The development of AQUM has only been made possible by initial developments of the UKCA project. In particular we wish to acknowledge the contributions made by O. Morgenstern, P. Young, G. Zeng and J. Pyle. The development of the UKCA model was supported by the Joint DECC/Defra Met Office Hadley Centre Climate Programme (GA01101) and the Natural Environment Research Council, through the NCAS initiative. Funding for AQUM is provided by the Met Office Public Weather Service. We are indebted to M. Sanderson for his assistance in the initial implementation of the RAQ chemistry scheme in AQUM. The speciated particulate matter data used in this paper are produced under contract to Defra and were kindly provided by S. Telling at AEA Technology and M. Twigg and C. Braban at the Centre for Ecology and Hydrology, Edinburgh. Data from the AURN are provided under contract to Defra by AEA Technology. Data from the MACC project were kindly provided by F. Cheroux of Meteo-France. This study contributes to COST Action ES1004 on online integrated modelling. Finally, we wish to thank the anonymous reviewers whose comments have helped clarify a number of points.

Edited by: P. Jöckel

\section{References}

Ackermann, I. H., Hass, H., Memmesheimer, M., Ziegenbein, C., and Ebel, A.: The parametrization of the sulphate-nitrateammonia aerosol system in the long-range transport model EURAD, Meteorol. Atmos. Phys., 57, 101-114, 1995.

Agnew, P., Mittermaier, M. P., Honore, C., Elbern, H., Coll, I., Vautard, R., and Peuch., V.-H.: Evaluation of GEMS regional air quality forecasts, GEMS project report, available at: http://gems.ecmwf.int/do/get/PublicDocuments/1533/1402? showfile=true (last access: 4 January 2013), 2007.

Andres, R. J. and Kasgnoc, A. D.: A time-averaged inventory of sub-aerial volcanic sulfur emissions, J. Geophys. Res. Atmos., 103, 25251-25261, 1998.

Bellouin, N., Rae, J., Jones, A., Johnson, C., Haywood, J., and Boucher, O.: Aerosol forcing in the Climate Model Intercomparison Project (CMIP5) simulations by HadGEM2-ES and the role of ammonium nitrate, J. Geophys Res.-Atmos., 116, D20206, doi:10.1029/2011JD016074, 2011.

Bellouin, N., Mann, G. W., Woodhouse, M. T., Johnson, C., Carslaw, K. S., and Dalvi, M.: Impact of the modal aerosol scheme GLOMAP-mode on aerosol forcing in the Hadley Centre Global Environmental Model, Atmos. Chem. Phys. Discuss., 12, 21437-21479, doi:10.5194/acpd-12-21437-2012, 2012.

Bieser, J., Aulinger, A., Matthias, V., Quante, M., and Denier van der Gon, H. A. C.: Vertical emission profiles for Europe based on plume rise calculations, Environ. Poll., 159, 2935-2946, doi:10.1016/j.envpol.2011.04.030, 2011.

Bush, M., Bell, S., Christidis, N., Renshaw, R., MacPherson, B., and Wilson, B.: Development of the North Atlantic European model (NAE) into an operational model, Forecasting Research Technical Report No. 47, Met Office, UK, 2006.

Collins, W. J., Stevenson, D. S., Johnson, C. E., and Derwent, R. G.: Tropospheric ozone in a global-scale three-dimensional Lagrangian model and its response to $\mathrm{NO}_{\mathrm{x}}$ emission controls, J. Atmos. Chem., 26, 223-274, 1997.
Collins, W. J., Stevenson, D. S., Johnson, C. E., and Derwent, R. G.: Role of convection in determining the budget of odd hydrogen in the upper troposphere, J. Geophys. Res. Atmos., 104, 26927 26941, 1999.

Collins, W. J., Bellouin, N., Doutriaux-Boucher, M., Gedney, N., Halloran, P., Hinton, T., Hughes, J., Jones, C. D., Joshi, M., Liddicoat, S., Martin, G., O’Connor, F., Rae, J., Senior, C., Sitch, S., Totterdell, I., Wiltshire, A., and Woodward, S.: Development and evaluation of an Earth-System model - HadGEM2, Geosci. Model Dev., 4, 1051-1075, doi:10.5194/gmd-4-10512011, 2011.

Cox, W. M. and Tikvart, J. A.: A statistical procedure for determining the best performing air quality simulation model, Atmos. Environ., 24A, 2387-2395, 1990.

Davies, H. C.: A lateral boundary formulation for multi-level prediction models, Q. J. Roy. Meteor. Soc., 102, 405-418, 1976.

Davies, T.: Lateral boundary conditions for limited area models, Q. J. Roy. Meteor. Soc., accepted, 2013.

Davies, T., Cullen, M. J. P., Malcolm, A. J., Mawson, M. H., Staniforth, A., White, A. A., and Wood, N.: A new dynamical core for the Met Office's global and regional modelling of the atmosphere, Q. J. Roy. Meteor. Soc., 131, 1759-1782, 2005.

Derwent, R. G., Jenkin, M. E., Collins, W. J., Johnson, C. E., and Stevenson, D. S.: The global distribution of secondary particulate matter in a 3-D Lagrangian chemistry transport model, J. Atmos. Chem., 44, 57-95, 2003.

Dore, C. J., Murrells, T. P., Passant, N. R., Hobson, M. M., Thistlethwaite, G., Wagner, A., Li, Y., Bush, T., King, K. R., Norris, J., Coleman, P. J., Walker, C., Stewart, R. A., Tsagatakis, I., Conolly, C., Brophy, N. C. J., and Hann, M. R.: UK emissions of air pollutants 1970 to 2006, available at: http://uk-air.defra.gov.uk/reports/cat07/ 0810291043_NAEI_2006_Report_Final_Version(3).pdf (last access: 4 January 2013), 2008.

Dunlea, E. J., Herndon, S. C., Nelson, D. D., Volkamer, R. M., San Martini, F., Sheehy, P. M., Zahniser, M. S., Shorter, J. H., Wormhoudt, J. C., Lamb, B. K., Allwine, E. J., Gaffney, J. S., Marley, N. A., Grutter, M., Marquez, C., Blanco, S., Cardenas, B., Retama, A., Ramos Villegas, C. R., Kolb, C. E., Molina, L. T., and Molina, M. J.: Evaluation of nitrogen dioxide chemiluminescence monitors in a polluted urban environment, Atmos. Chem. Phys., 7, 2691-2704, doi:10.5194/acp-7-2691-2007, 2007.

Edwards J. M. and Slingo, A.: Studies with a flexible new radiation code, 1. Choosing a configuration for a large-scale model, Q. J. Roy. Meteor. Soc., 122, 689-719, 1996.

Essery, R. L. H., Best, M. J., Betts, R. A., Cox, P. M., and Taylor, C. M.: Explicit representation of subgrid heterogeneity in a GCM land surface scheme, J. Hydrometeorol., 4, 530-543, 2003.

Eyers, C. J., Norman, P., Middel. J., Plohr, M., Atkinson, K., and Christou, R. A.: Aero2k global aviation emission inventories for 2002 and 2025, available at: http://www.aero-net.org/pdf-docs/AERO2K_Global_Aviation_ Emissions_Inventories_for_2002_and_2025.pdf (last access: 4 January 2013), 2004.

Flemming, J., Inness, A., Flentje, H., Huijnen, V., Moinat, P., Schultz, M. G., and Stein, O.: Coupling global chemistry transport models to ECMWF's integrated forecast system, Geosci. Model Dev., 2, 253-265, doi:10.5194/gmd-2-253-2009, 2009. 
Giannakopoulos, C.: Three dimensional modelling of the concentration and deposition of tropospheric trace gases, Ph.D. thesis, University of Cambridge, UK, 1998.

Giannakopoulos, C., Chipperfield, M. P., Law, K. S., and Pyle J. A.: Validation and intercomparison of wet and dry deposition schemes using $\mathrm{Pb}-210$ in a global three-dimensional off-line chemical transport model. J. Geophys. Res. Atmos., 104, 2376123784, 1999.

Gregory, D. and Rowntree, P. R.: A Mass Flux Convection Scheme With Representation Of Cloud Ensemble Characteristics And Stability-Dependent Closure, Mon. Weather Rev., 118, 1483 1506, 1990.

Hollingsworth, A., Engelen, R. J., Benedetti, A., Dethof, A., Flemming, J., Kaiser, J. W., Morcrette, J.-J., Simmons, A. J., Textor, C., Boucher, O., Chevallier, F., Rayner, P., Elbern, H., Eskes, H., Granier, C., Peuch, V.-H., Rouil, L., and Schultz, M. G.: Toward a monitoring and forecasting system for atmospheric composition: The GEMS project, B. Am. Meteorol. Soc., 89, 1147-1164, 2008.

Jones, A., Roberts, D. L., Woodage, M. J., and Johnson, C. E.: Indirect sulphate aerosol forcing in a climate model with an interactive sulphur cycle, J. Geophys. Res. Atmos., 106, 20293-20310, 2001.

Kettle, A. J., Andreae, M. O., Amouroux, D., Andreae, T. W., Bates, T. S., Berresheim, H., Bingemer, H., Boniforti, R, Curran, M. A. J., DiTullio, G. R., Helas, G., Jones, G. B., Keller, M. D., Kiene, R. P., Leck, C., Levasseur, M., Malin, G., Maspero, M., Matrai, P., McTaggart, A. R., Mihalopoulos, N., Nguyen, B. C., Novo, A., Putaud, J. P., Rapsomanikis, S., Roberts, G., Schebeske, G., Sharma, S., Simo, R., Staubes, R., Turner, S., and Uher, G.: A global database of sea surface dimethylsulfide (DMS) measurements and a procedure to predict sea surface DMS as a function of latitude, longitude, and month, Glob. Biogeochem. Cy., 13, 399-444, 1999.

Lamsal, L. N., Martin, R. V., van Donkelaar, A., Steinbacher, M., Celarier, E. A., Bucsela, E., Dunlea, E. J., and Pinto, J. P.: Ground-level nitrogen dioxide concentrations inferred from the satellite-borne Ozone Monitoring Instrument, J. Geophys. Res., 113, D16308, doi:10.1029/2007JD009235, 2008.

Lamsal, L. N., Martin, R. V., van Donkelaar, A., Celarier, E. A., Bucsela, E. J., Boersma, K. F., Dirksen, R., Luo, C., and Wang, Y.: Indirect validation of tropospheric nitrogen dioxide retrieved from the OMI satellite instrument: Insight into the seasonal variation of nitrogen oxides at northern midlatitudes, J. Geophys. Res., 115, D05302, doi:10.1029/2009JD013351, 2010.

Lock, A. P., Brown, A. R., Bush, M. R., Martin, G. M., and Smith, R. N. B.: A new boundary layer mixing scheme. Part I: Scheme description and single-column model tests, Mon. Weather Rev., 128, 3187-3199, 2000.

MacCarthy, J., Pang, Y., Murrells, T. P., Passant, N., Martinez, C., Thomas, J., Thistlethawaite, G., and Misselbrook, T.: Air quality pollutant inventories for England, Scotland, Wales and Northern Ireland: 1990-2009, AEA report number AEAT/ENV/R/3225, 2011.

Mann, G. W., Carslaw, K. S., Spracklen, D. V., Ridley, D. A., Manktelow, P. T., Chipperfield, M. P., Pickering, S. J., and Johnson, C. E.: Description and evaluation of GLOMAP-mode: a modal global aerosol microphysics model for the UKCA composition-climate model, Geosci. Model Dev., 3, 519-551, doi:10.5194/gmd-3-519-2010, 2010.

Mareckova, K., Wankmueller, R., Pazdernik, K., Purzner, M., Zechmeister, A., Joebstl, R., and Adams, M.: Inventory Review 2010, Review of emission data reported under the LRTAP Convention and NEC Directive Stage 1 and 2 review, Status of gridded data and LPS data, Umweltbundesamt GmbH, Vienna, ISBN 978-399004-095-9, 2010.

Menut, L., Goussebaile, A., Bessagnet, B., Khvorostiyanov, D., and Ung, A.: Impact of realistic hourly emissions profiles on air pollutants concentrations modelled with CHIMERE, Atmos. Environ., 49, 233-244, 2012.

Met Office, June 2010 Climate Summary, Exeter, UK, available at: http://www.metoffice.gov.uk/climate/uk/2010/june.html (last access: 4 January 2013), 2010.

Met Office: April 2011 Climate Summary, Exeter, UK, available at: http://www.metoffice.gov.uk/climate/uk/2011/april.html (last access: 4 January 2013), 2011.

Met Office: UK Climate Summaries, Exeter, UK, available at: http://www.metoffice.gov.uk/climate/uk/, (last access: 4 January 2013), 2012.

Moinat, P. and Marecal, V.: ENSEMBLE regional forecasting system and performances (issue 1), available at: http://www.gmes-atmosphere.eu/documents/maccii/ deliverables/ens/D_ENS_ENSEMBLE_Dossier1_finalv.pdf (last access: 4 January 2013), 2012.

Monks, P. S.: A review of the observations and origins of the spring ozone maximum, Atmos. Environ., 34, 3545-3561, 2000.

Morgenstern, O., Braesicke, P., O’Connor, F. M., Bushell, A. C., Johnson, C. E., Osprey, S. M., and Pyle, J. A.: Evaluation of the new UKCA climate-composition model - Part 1: The stratosphere, Geosci. Model Dev., 2, 43-57, doi:10.5194/gmd-2-432009, 2009.

Morgenstern, O., Braesicke, P., O'Connor, F. M., Bushell, A. C., Johnson, C. E., Osprey, S. M., and Pyle, J. A.: Evaluation of the new UKCA climate-composition model - Part 1: The stratosphere, Geosci. Model Dev., 2, 43-57, doi:10.5194/gmd-2-432009, 2009.

O'Connor, F. M., Johnson, C. E., Morgenstern, O., Abraham, N. L., Braesicke, P., Dalvi, M., Folberth, G. A., Sanderson, M. G., Telford, P. J., Young, P. J., Zeng, G., Collins, W. J., and Pyle, J. A.: Evaluation of the new UKCA climate-composition model Part 2: The Troposphere, Geosci. Model Dev. Discuss., 6, 1743 1857, doi:10.5194/gmdd-6-1743-2013, 2013.

O'Dowd, C. D., Lowe, J. A., and Smith, M. H.: Coupling seasalt and sulphate interactions and its impact on cloud droplet concentration predictions, Geophys. Res. Lett., 26, 1311-1314, doi:10.1029/1999GL900231, 1999.

Poupkou, A., Giannaros, T., Markakis, K. Kioutsioukis, I., Curci, G., Melas, D., and Zerefos, C.: A model for European biogenic volatile organic compound emissions: Software development and first validation, Environ. Modell. Softw., 25, 1845-1856, 2010.

Pregger, T. and Friedrich, R.: Effective pollutant emission heights for atmospheric transport modelling based on real-world information, Environ. Poll., 157, 552-560, doi:10.1016/j.envpol.2008.09.027, 2009.

Price, J. D., Vosper, S., Brown, A., Ross, A., Clark, P., Davies, F., Horlacher, V., Claxton, B., McGregor, J. R., Hoare, J. S., Jemmett-Smith, B., and Sheridan, P.: COLPEX: Field and numerical studies over a region of small hills, B. Am. Meteorol. 
Soc., 92, 1636-1650, 2011.

Randerson, J. T., Kasibhatla, P. S., Kasischke, E. S., Hyer, E. J., Giglio, L., Collatz, G. J., and van der Werf G. R.: Global fire emissions database (GFED), version 1, available at: http://daac. ornl.gov (last access: 2 October 2012), 2005.

Sanderson, M. G., Collins, W. J., Hemming, D. L., and Betts, R. A.: Stomatal conductance changes due to increasing carbon dioxide levels: Projected impact on surface ozone levels, Tellus, 59B, 404-411, 2007.

Schere, K., Flemming, J., Vautard, R., Chemel, C., Colette, A., Hogrefe, C., Bessagnet, B., Meleux, F., Mathur, R., Roselle, S., Hu, R.-M., Sokhi, R. S., Rao, S. T., and Galmarini, S.: Trace gas/aerosol boundary concentrations and their impacts on continental-scale AQMEII modeling domains, Atmos. Environ., 53, 38-50, 2012.

Seigneur, C., Pun, B., Pai, P., Louis, J-F., Solomom, P., Emery, C., Morris, R., Zahniser, M., Worsnop, D., Koutrakis, P., White, W., and Tombach, I.: Guidance for the performance evaluation of three dimensional air quality modelling systems for particulate matter and visibility, J. Air Waste Manage. Assoc., 50, 588-599, 2000.

Smith, R. N. B.: A Scheme for Predicting Layer Clouds and Their Water-Content in a General-Circulation Model, Q. J. Roy. Meteor. Soc., 116, 435-460, 1990.

Stacey, S. E. B.: QA/QC Data Ratification Report for the Automatic Urban and Rural Network, October-December 2011, and Annual Report 2011, available at: http://uk-air.defra.gov.uk/reports/ cat05/1207040912_AURN_2011_Q4_Issue_1.pdf (last access: 4 January 2013), 2012.

Steinbacher, M., Zellweger, C., Schwarzenbach, B., Bugmann, S., Buchmann, B., Ordóñez, C., Prevot, A. S. H., and Hueglin, C.: Nitrogen oxide measurements at rural sites in Switzerland: Bias of conventional measurement techniques, J. Geophys. Res. Atmos., 112, D11307, doi:10.1029/2006JD007971, 2007.
Stephenson, D.: Use of the "Odds Ratio" for diagnosing forecast skill, Weather Forecast., 15, 221-232, 2000.

Vidic, S.: Frequency distributions of effective plume height, Internal Technical Note, EMEP, 10 September 2002, Croatian Meteorological and Hydrological Service, Zagreb, Croatia, 2002.

Visschedijk, A., Zanveld, P., and van der Gon, H.: A high resolution gridded European emission database for the EU integrated project GEMS, TNO report 2007-A-R0233/B., 2007.

Wanninkhof, R.: Relationship Between Wind-Speed And GasExchange Over The Ocean, J. Geophys. Res. Oceans, 97, 73737382, 1992.

Wesley, M. L.: Parameterization Of Surface Resistances To Gaseous Dry Deposition In Regional-Scale Numerical-Models, Atmos. Environ., 23, 1293-1304, 1989.

Whall, C., Scarborough, T., Stavrakaki, A., Green, C., Squire, J., and Noden, R.: UK Ship Emissions Inventory, Entec UK Ltd, London, UK, available at: http://uk-air.defra.gov.uk/reports/ cat15/1012131459_21897_Final_Report_291110.pdf (last access: 4 January 2013), 2010.

Wild, O., Zhu, X., and Prather, M. J.: Fast-J: Accurate simulation of in- and below-cloud photolysis in tropospheric chemical models, J. Atmos. Chem., 37, 245-282, 2000.

Wilks, D. S.: Statistical Methods in the Atmospheric Sciences, 2nd Edn., Academic Press, London, 2006.

Wilson, D. R. and Ballard, S. P.: A micro-physically based precipitation scheme for the UK Meteorological Office Unified Model, Q. J. Roy. Meteor. Soc., 125, 1607-1636, 1999. 